Research Article

\title{
Investment Decision of New Energy Vehicle Enterprises Using the Interval Basic Probability Assignment-Based Intuitionistic Fuzzy Set
}

\author{
Xin Kang $\mathbb{D}^{1},{ }^{1}$ Xiangjun $X u \mathbb{D}^{1},{ }^{1}$ and Fei Yuan $\mathbb{D}^{2}$ \\ ${ }^{1}$ School of Economics and Management, Harbin University of Science and Technology, Harbin 150040, China \\ ${ }^{2}$ College of Economics and Management, Beijing University of Technology, Beijing 100124, China \\ Correspondence should be addressed to Fei Yuan; yuan@bjut.edu.cn
}

Received 2 March 2021; Accepted 23 April 2021; Published 26 May 2021

Academic Editor: Alessandro Rasulo

Copyright (c) 2021 Xin Kang et al. This is an open access article distributed under the Creative Commons Attribution License, which permits unrestricted use, distribution, and reproduction in any medium, provided the original work is properly cited.

To evaluate the investment decisions of new energy vehicle enterprises scientifically and reasonably and improve the investment efficiency and accuracy of decision-makers, this paper proposes an investment decision method based on interval intuitionistic fuzzy sets. In the investment decision-making process of new energy vehicle enterprises, first, based on the characteristics of new energy vehicle enterprise investment projects, an index system is constructed to comprehensively cover the influencing factors of investment decisions. Second, we obtain the interval fuzzy number of the decision index through a questionnaire survey, use the structural entropy method to empower decision indicators, and comprehensively evaluate the decision index by the organic combination of the interval-valued intuitionistic fuzzy weighted averaging (IIFWA) operator and structural entropy method. Finally, interval BPA is used to express the value of each decision index interval intuitionistic fuzzy number. Based on the conversion relationship between interval evidence and the intuitionistic fuzzy set, the orthogonal sum operation results of the intuitionistic fuzzy set converted from the normalized interval BPA is replaced by the interval evidence combination result, and the final decision is determined by comparing the fusion result. Applying the investment decision method based on interval intuitionistic fuzzy sets to the field of new energy vehicle investment decision-making can provide a reference for investment decision-makers to make efficient and accurate decisions, and it has application value and practical significance to promote the effective development of new energy investment decisions.

\section{Introduction}

In 2019, the new EU institutions put the promotion of the green transformation of the EU economy and society in the first place, not only proposing and implementing the "Green Agreement" but also regarding the "Green Renaissance" as the priority means to restore the economy after the new coronavirus pneumonia epidemic. The aim is to create a circular economy and achieve economic growth and use of resource "decoupling." Under the predicament of low international oil prices and weak global economic recovery, many European oil companies, such as Repsol, BP, Shell, Eni, and Total, have successively announced the strategic goal of achieving net zero carbon emissions by 2050 . This reflects the urgent requirements of the international community for the low-carbon transformation of traditional energy-dependent products. As an important pillar of the national economy of all countries in the world, the vehicle industry has always been highly dependent on traditional energy sources. A series of problems have arisen, such as the shortage of fossil energy, excessive emissions of pollutants such as carbon dioxide, and serious air pollution. In this context, the promotion of energy conservation, emission reduction, and green transformation and upgrading of the auto industry has become the consensus of the global auto industry.

Because the new energy automobile industry faces risks such as disruptive technological innovation expectations and market demand uncertainty, relying solely on the strong support of national finance and industrial policies will inevitably face many problems in the operation process. 
Among them, investment decision-making issues are particularly prominent. For example, Sichuan Western Resources Holdings Co., Ltd., attracted by the massive profits of the new energy vehicle industry, announced its involvement in the new energy vehicle field to obtain high returns. However, before the order for the first new energy vehicle was converted into continuous cash flow, Chongqing Hengtong Bus Co., Ltd., under its subsidiary caused the loss of some orders due to fraud problems, a substantial decline in financing capacity, and a tight liquidity flow. This directly caused the net profit of Sichuan Western Resources Holdings Co., Ltd., to plummet from 16 million in 2014 to a loss of 599 million in 2017. In the first quarter of 2018, the inventory reached 300 million, and the accounts receivable and payable also reached 200 million yuan, with an asset-liability ratio as high as $81 \%$. To avoid Chongqing Hengtong Bus Co., Ltd., from adversely affecting the performance of Western Resources, Western Resources decided to divest it and use the cash assets obtained to repay part of the interest-bearing debts, supplement liquidity, and ease financial pressure. Therefore, the investment decisions of new energy vehicle enterprises play a vital role in their business development. Enterprises urgently need to seek a set of scientific and reasonable methods to ensure that investment decisions effectively promote the stable operation of enterprises.

In the investment decision-making process of new energy vehicle enterprises, many decision-making indicators are involved. These indicators are usually difficult to quantitatively analyze, such as the richness of resources and the availability of resources. It is necessary to use a reasonable method to characterize these indicators and aggregate the evaluation information of these decision-making indicators according to the corresponding indicator weights and the aggregator.

As an important part of modern scientific decisionmaking, multiple attribute decision-making based on fuzzy theory is widely used in the economy, society, management, military, engineering, and other aspects. The concept of multiattribute group decision-making was first proposed by Churchman et al., who defined multiattribute group decision-making as the problem of selecting or sorting the optimal alternatives while taking into account multiple attributes of the decision object [1]. In the actual application of multiattribute group decision-making, because of the ambiguity of thinking, the limitation of cognition, and the complexity of the decision-making environment, it is usually difficult for people to use accurate data to evaluate objective things with multiple attributes at the same time $[2,3]$. The same is true for new energy investment decisions as a preassessment before the investment plan is launched. Some indicators that are difficult to quantify in the decisionmaking process do not have accurate statistical data and are only based on the experience of relevant experts and scholars and relevant research results in an attempt to make qualitative and fuzzy evaluations of such indicators. Some research results have examined the new energy investment decision-making problem from the perspective of fuzzy evaluation, but the research results mostly focus on improving the accuracy of the experts' assignment of decision- making indicators and fail to fully consider the potential information uncertainty in the decision-making process [4-6]. To solve the above problems, as a pioneer of fuzzy set theory, Zadeh used fuzzy set theory for the first time to process fuzzy information in a way that the degree of membership represents evaluation information [7]. On this basis, considering the opposite information of membership degree, Atanassov proposed the concept of intuitionistic fuzzy sets. Through the introduction of membership functions, nonmembership functions, and hesitation functions, the uncertainty of decision information and the ambiguity of human cognition are described in a comprehensive and detailed manner [8]. Furthermore, considering that it is difficult to assign precise values to membership and nonmembership in decision-making, some scholars proposed interval intuitionistic fuzzy sets. Because of its significant advantages in fuzzy information processing, it has been valued and recognized by scholars at home and abroad [9-12]. In the multiattribute group decision-making problem, different decision-makers or experts give different degrees of support for each plan. As a result, it is more difficult to gather all expert opinions and form a definite conclusion [13]. Therefore, it is necessary to use evidence theory modeling to obtain sufficient and effective information before making the final decision. D-S evidence theory is an imprecise reasoning theory established and perfected by Dempster and Shafer $[14,15]$. After nearly half a century of development, D-S evidence theory has become an important information fusion tool, with significant application effects in the fields of pattern recognition [16], decision analysis [17], clustering combination [18], and so on. In D-S evidence theory, the basic probability distribution function (BPA) focuses on the basic probability mass (BPM) of all focal elements to determine the exact BPA of the real number. However, in the actual decision fusion problem, the subjective judgment of decision-makers is generally uncertain, and different decision-makers have different degrees of support for each decision plan [19]. It is difficult to centralize the opinions of all decision-makers; therefore, accurate BPA cannot be obtained as evaluation data [20]. In recent years, many scholars have tried to reasonably solve this problem by extending the evidence combination rule in D-S evidence theory to interval evidence theory. That is, the basic probability distribution function is expressed by the interval number, and the interval $\mathrm{BPA}$ is constructed to accurately model the uncertain information to realize the combination of interval evidence and effectively avoid the serious loss of information [21-25].

The existing research results have introduced a variety of interval evidence combination methods and provide an excellent way to integrate investment decision index evaluation results. However, most of these methods use optimization models to determine the upper and lower bounds of each BPM in the fusion result. Such optimization algorithms have high complexity and cannot integrate multiple interval evidence in sequence, which makes it difficult to meet the needs of time-domain information fusion. Therefore, this paper aims to construct an interval evidence combination method based on intuitionistic fuzzy sets. First, 
the interval intuitionistic fuzzy number of the decision index is represented in the form of interval BPA. Second, based on the conversion relationship between interval evidence and intuitionistic fuzzy sets, the normalized interval BPA is transformed into an intuitionistic fuzzy set, and an orthogonal sum operation is performed. Finally, the orthogonal sum operation result of the intuitionistic fuzzy set is replaced by the normalized interval evidence combination result to determine the superiority and inferiority order of the decision-making plan. Compared with the existing combination method, this method can flexibly combine multiple interval evidence in sequence. It can effectively reduce the time on the premise of obtaining a reasonable combination result, and the algorithm complexity is much lower than that of the existing methods [26].

The innovation of this paper that makes it different from the traditional thinking mode of decision-making is that integrates the IIFWA integration operator and the structural entropy method through the comprehensive evaluation method throughout the decision-making process. The purposes of the paper are to effectively solve the problem of information loss in the decision-making process, further enhance the reliability of the decision result, and obtain reasonable integration results while improving the efficiency of investors' decision-making. This paper introduces an interval evidence combination method based on intuitionistic fuzzy sets in the final decision-making stage. First, the obtained uncertain interval intuitionistic fuzzy number is converted into a definite interval BPA and the orthogonal sum operation is performed on the intuitionistic fuzzy set formed by the normalized interval BPA. Then, the logical relationship between interval evidence and intuitionistic fuzzy sets is used to replace the orthogonal sum operation result in the result of the interval evidence combination. Finally, the decision plan is determined through the above operations. Applying the investment decision method based on interval intuitionistic fuzzy sets to the field of new energy vehicle investment decision-making can provide strong theoretical support and guidance for investment decisionmakers to make efficient and accurate decisions. It fills the gaps in the current investment decision-making methods field of new energy vehicles, and it has application value and practical significance to promote the effective development of new energy investment decisions.

The rest of the paper is organized as follows. Section 2 briefly reviews the related concepts of interval evidence and interval intuitionistic fuzzy sets and the method of interval evidence combination based on intuitionistic fuzzy sets. Section 3 proposes a new energy vehicle enterprise investment decision model based on five aspects: building a decision-making index system, obtaining decision index measurements, determining decision-making index weights, comprehensively evaluating the attributes of decision-making indexes, and fusing decision index evaluation results. Section 4 takes specific data as an example. The investment decision model is actually applied to the investment simulation decision-making process of new energy vehicle enterprises. Section 5 compares the method used in this paper with the same type of method to reflect the rationality and superiority of the method, and Section 6 summarizes the research conclusion of this article.

\section{Preliminary}

2.1. Interval Evidence Theory. D-S evidence theory determines the support of the evidence for each proposition based on the identification framework and expresses the support of all the propositions by using the evidence combination formula to calculate the evidence in the form of a set. The identification framework $\Theta=\left\{\theta_{1}, \theta_{2}, \ldots, \theta_{n}\right\}$ is a collection of all mutually incompatible results of a multiattribute group decision-making problem and uses the correspondence between propositions and collections to transform abstract logical concepts into image collection concepts [27].

Definition 1. Set $\Theta=\left\{\theta_{1}, \theta_{2}, \ldots, \theta_{n}\right\}$ as the identification frame, and $2^{\Theta}$ represents the power set consisting of all subsets on the identification frame $\Theta$. The function $m: 2^{\Theta} \longrightarrow[0,1]$ satisfying $m(\phi)=0$ and $\sum m(A)=1$ is called the basic probability assignment function (BPA), where $\phi$ represents the empty set, $\forall A \subseteq \Theta$. If it satisfies $m(A)>0, A$ is called the focal element of $\Theta$.

As an extended form of D-S evidence theory, interval evidence theory achieves sufficient decision-making information through accurate modeling of uncertain information. In the actual group decision problem, constructing interval BPA is more conducive to final decision-making than accurate BPA.

Definition 2. Set $\Theta=\left\{\theta_{1}, \theta_{2}, \ldots, \theta_{n}\right\}$ as the identification frame if the basic probability quality interval number $\left[a_{1}, b_{1}\right],\left[a_{2}, b_{2}\right], \ldots,\left[a_{N}, b_{N}\right]$ of all subsets $F_{1}, F_{2}, \ldots, F_{N}$ on the identification frame $\Theta$ satisfies the following conditions:

$$
\begin{aligned}
a i & \leq m\left(F_{i}\right) \leq b_{i}, \\
\sum_{i=1}^{N} a_{i} & \leq 1, \\
\sum_{i=1}^{N} b_{i} & \geq 1, \\
m(H) & =0, \quad \forall H \notin\left\{F_{1}, F_{2}, \ldots, F_{N}\right\} .
\end{aligned}
$$

Then, $m$ is called the interval basic probability assignment function (interval BPA), and the Bayesian probability distribution of the single-element subset with all focal elements equal to $\Theta$ in the identification framework is called the interval Bayesian BPA, which is expressed as

$$
\begin{aligned}
\operatorname{Bet} P_{m}(\{\theta j\}) & =\left[\operatorname{Bet} P_{m}^{-}\left(\left\{\theta_{j}\right\}\right), \operatorname{Bet} P_{m}^{+}\left(\left\{\theta_{j}\right\}\right)\right] \\
& =\left\{\sum_{\theta j \in F_{i}} \frac{a_{i}}{\left|F_{i}\right|}, \min \left[1, \sum_{\theta j \in F_{i}} \frac{b_{i}}{\left|F_{i}\right|}\right]\right\},
\end{aligned}
$$

where $0 \leq a_{i} \leq b_{i} \leq 1, i=1,2, \ldots, N, j=1,2, \ldots, n$. 
Definition 3. Set $m$ as the interval BPA on the identification frame $\Theta=\left\{\theta_{1}, \theta_{2}, \ldots, \theta_{n}\right\}$, and all its focal elements are $F_{1}, F_{2}, \ldots, F_{N}$ if $a j$ and $b j$ satisfy the following conditions:

$$
\begin{aligned}
& \sum_{j=1}^{N} b_{j}-\left(b_{k}-a_{k}\right) \geq 1, \\
& \sum_{j=1}^{N} a_{j}+\left(b_{k}-a_{k}\right) \leq 1 .
\end{aligned}
$$

Then, $m$ is called the normalized interval BPA, where $j=1,2, \ldots, N$ and $\forall k \in\{1,2, \ldots, N\}$.

Wang and Elhag divided the nonnormalized interval BPA into two categories [24]. The first category is the nonnormalized interval $\mathrm{BPA}$ that does not satisfy $\sum_{j=1}^{N} a_{j} \leq 1$ and $\sum_{j=1}^{N} b_{j} \geq 1$. The normalization formula is as follows:

$$
\begin{gathered}
\widehat{a}_{i}=\frac{a_{i}}{a_{i}+\sum_{j=1, j \neq i}^{N} b_{j}}, \quad i=1,2, \ldots, N, \\
\widehat{b}_{i}=\frac{b_{i}}{b_{i}+\sum_{j=1, j \neq i}^{N} a_{j}}, \quad i=1,2, \ldots, N .
\end{gathered}
$$

The second category is the nonnormalized interval BPA that satisfies $\sum_{j=1}^{N} a_{j} \leq 1$ and $\sum_{j=1}^{N} b_{j} \geq 1$ but does not satisfy $\sum_{j=1}^{N} b_{j}-\left(b_{k}-a_{k}\right) \geq 1$ and $\sum_{j=1}^{N} a_{j}+\left(b_{k}-a_{k}\right) \leq 1$. The normalization formula is as follows:

$$
\begin{aligned}
& \widehat{a}_{i}=\max \left\{a_{i}, 1-\sum_{j=1, j \neq i}^{N} b_{j}\right\}, \quad i=1,2, \ldots, N, \\
& \widehat{b}_{i}=\min \left\{b_{i}, 1-\sum_{j=1, j \neq i}^{N} a_{j}\right\}, \quad i=1,2, \ldots, N .
\end{aligned}
$$

2.2. Interval Intuitionistic Fuzzy Sets. Atanassov first proposed the concept of intuitionistic fuzzy sets and described the ambiguity in random phenomena. The membership function, nonmembership function, and hesitation function are used to describe fuzzy information in detail [8].

Definition 4. Set $X=\left\{x_{1}, x_{2}, \ldots, x_{n}\right\}$ as the universe of nonempty sets and define the intuitionistic fuzzy set $A$ in the universe $X$ as

$$
A=\left\{\left\langle x, \mu_{A}(x), v_{A}(x)\right\rangle \mid x \in X\right\},
$$

where $\mu_{A}(x): X \longrightarrow[0.1]$ and $v_{A}(x): X \longrightarrow[0.1]$ denote the membership function and the nonmembership function, respectively, satisfying the following conditions:

$$
0 \leq \mu_{A}(x)+v_{A}(x) \leq 1 .
$$

The expression of the hesitation function $\pi_{A}(x): X \longrightarrow$ [0.1] is given by

$$
\pi_{A}(x)=1-\mu_{A}(x)-v_{A}(x) .
$$

Due to the uncertainty of the fuzzy information in the actual group decision-making problem, it is usually difficult to obtain the exact values of $\mu_{A}(x)$ and $v_{A}(x)$ to represent the specific value of the intuitionistic fuzzy number $\alpha=\left\langle\mu_{A}(x), v_{A}(x)\right\rangle$. Therefore, Atanassov et al. extended the concept of intuitionistic fuzzy sets and proposed the concept of interval intuitionistic fuzzy sets [28]. Accordingly, the membership function and nonmembership function expressed by interval numbers are transformed into membership interval and nonmembership interval, respectively, and the ordered interval composed of the membership interval and nonmembership interval is called the interval intuitionistic fuzzy number. To distinguish it from the intuitionistic fuzzy number, it is recorded as $\alpha=\left\langle\left[\mu_{A}^{L}(x), \mu_{A}^{R}(x)\right],\left[v_{A}^{L}(x), v_{A}^{R}(x)\right]\right\rangle$.

Definition 5. Setting $X=\left\{x_{1}, x_{2}, \ldots, x_{n}\right\}$ as the universe of nonempty sets, the interval intuitionistic fuzzy sets $A$ in the universe $X$ can be defined as

$$
A=\left\{\left\langle x,\left[\mu_{A}^{L}(x), \mu_{A}^{R}(x)\right],\left[v_{A}^{L}(x), v_{A}^{R}(x)\right]\right\rangle \mid x \in X\right\},
$$

where $\left[\mu_{A}^{L}(x), \mu_{A}^{R}(x)\right]$ and $\left[v_{A}^{L}(x), v_{A}^{R}(x)\right]$ denote the membership degree interval and the nonmembership degree interval, respectively, and the hesitation degree interval can be expressed as

$$
\pi A(x)=\left[1-\mu_{A}^{R}(x)-v_{A}^{R}(x), 1-\mu_{A}^{L}(x)-v_{A}^{L}(x)\right] .
$$

2.3. Interval Evidence Combination Method Based on Intuitionistic Fuzzy Sets. Based on the perspective of set theory, the BPA $m$ on the identification framework $\Theta=\left\{\theta_{1}, \theta_{2}, \ldots\right.$, $\left.\theta_{n}\right\}$ of evidence theory is regarded as the intuitionistic fuzzy set $M$ on the domain $\Theta=\left\{\theta_{1}, \theta_{2}, \ldots, \theta_{n}\right\}$. Let $\mu\left(\theta_{i}\right)$ represent the membership function relative to the intuitionistic fuzzy set $\theta i$ and $v\left(\theta_{i}\right)$ represent the nonmembership function relative to the intuitionistic fuzzy set $\theta_{i}$. If all the focal elements of BPA $m$ are gathered in a single-element focal element, the trust degree of each focal element is the intuitive blur number $\left\langle\mu\left(\theta_{i}\right), v\left(\theta_{i}\right)\right\rangle$. It can be regarded as the matching degree between the decision object $\theta_{i}$ and the decision plan [29].

Definition 6. Setting $m$ as the interval Bayesian BPA on the identification frame $\Theta=\left\{\theta_{1}, \theta_{2}, \ldots, \theta_{n}\right\}$, the intuitionistic fuzzification form of the single-element subset support $m\left(\left\{\theta_{i}\right\}\right)=\left[a_{i}, b_{i}\right]$ of the interval BPA $m$ is $\left\langle a_{i}, 1-b_{i}\right\rangle$ $(i=1,2, \ldots, n)$. Then, the intuitionistic fuzzy set $M$ on the universe $\Theta=\left\{\theta_{1}, \theta_{2}, \ldots, \theta_{n}\right\}$ corresponding to $m$ is expressed as

$$
M=\left\{\left\langle\theta_{i}, \mu\left(\theta_{i}\right), v\left(\theta_{i}\right)\right\rangle \mid i=1,2, \ldots, n\right\} .
$$

Moreover, there is the following correspondence: 


$$
\begin{aligned}
& \mu\left(\theta_{i}\right)=a_{i}, \\
& v\left(\theta_{i}\right)=1-b_{i}, \\
& \pi\left(\theta_{i}\right)=b_{i}-a_{i} .
\end{aligned}
$$

Based on the above description of the relationship between evidence theory and intuitionistic fuzzy sets, the intuitionistic fuzzy set $M$ on the universe $\Theta=\left\{\theta_{1}, \theta_{2}, \ldots, \theta_{n}\right\}$ transformed from $m$ is expressed as

$$
M i=\left\{\left\langle\theta_{i}, a_{i}, 1-b_{i}\right\rangle \mid i=1,2, \ldots, n\right\} .
$$

Definition 7. Setting $M_{1}=\left\{\left\langle\theta_{i}, \mu_{1}\left(\theta_{i}\right), v_{1}\left(\theta_{i}\right)\right\rangle \mid \theta_{i} \in \Theta\right\}, M_{2}=$ $\left\{\left\langle\theta_{i}, \mu_{2}\left(\theta_{i}\right), v_{2}\left(\theta_{i}\right)\right\rangle \mid \theta_{i} \in \Theta\right\}$ as two intuitionistic fuzzy sets on the universe $\Theta=\left\{\theta_{1}, \theta_{2}, \ldots, \theta_{n}\right\}$, the orthogonal sum operation result $M_{1} \oplus M_{2}$ of intuitionistic fuzzy sets $M_{1}$ and $M_{2}$ can be expressed as

$$
M_{1} \oplus M_{2}=\left\{\left\langle\theta_{i}, \frac{\mu_{1}\left(\theta_{i}\right)\left(1-v_{2}\left(\theta_{i}\right)\right)+\mu_{2}\left(\theta_{i}\right) \pi_{1}\left(\theta_{i}\right)}{1-\mu_{1}\left(\theta_{i}\right) v_{2}\left(\theta_{i}\right)-\mu_{2}\left(\theta_{i}\right) v_{1}\left(\theta_{i}\right)}, \frac{v_{1}\left(\theta_{i}\right)\left(1-\mu_{2}\left(\theta_{i}\right)\right)+v_{2}\left(\theta_{i}\right) \pi_{1}\left(\theta_{i}\right)}{1-\mu_{1}\left(\theta_{i}\right) v_{2}\left(\theta_{i}\right)-\mu_{2}\left(\theta_{i}\right) v_{1}\left(\theta_{i}\right)}\right\rangle \mid i=1,2, \ldots, n\right\}
$$

Definition 8. Setting $m_{1}$ and $m_{2}$ as the normalized interval BPA on the identification frame $\Theta=\left\{\theta_{1}, \theta_{2}, \ldots, \theta_{n}\right\}$, the single-element subset supports of $m_{1}$ and $m_{2}$ are $m_{1}\left(\left\{\theta_{i}\right\}\right)=$ $\left[a_{1 i}, b_{1 i}\right]$ and $m_{2}\left(\left\{\theta_{i}\right\}\right)=\left[a_{2 i}, b_{2 i}\right]$. Then, the intuitionistic fuzzy sets $M_{1}$ and $M 2$ on domain $\Theta=\left\{\theta_{1}, \theta_{2}, \ldots, \theta_{n}\right\}$ corresponding to $m_{1}$ and $m_{2}$, respectively, are expressed as

$$
\begin{aligned}
& M_{1}=\left\{\left\langle\theta_{i}, a_{1 i}, 1-b_{1 i}\right\rangle \mid i=1,2, \ldots, n\right\}, \\
& M_{2}=\left\{\left\langle\theta_{i}, a_{2 i}, 1-b_{2 i}\right\rangle \mid i=1,2, \ldots, n\right\} .
\end{aligned}
$$

According to formula (18), the orthogonal sum operation $M_{1} \oplus M_{2}$ of intuitionistic fuzzy sets $M_{1}$ and $M_{2}$ can be expressed as

$$
M_{1} \oplus M_{2}=\left\{\left\langle\theta_{i}, \frac{a_{1 i} b_{2 i}+a_{2 i}\left(b_{1 i}-a_{1 i}\right)}{1-a_{1 i}-a_{2 i}+a_{1 i} b_{2 i}+a_{2 i} b_{1 i}}, \frac{b_{1 i}\left(1-a_{2 i}\right)+\left(1-b_{2 i}\right)\left(b_{1 i}-a_{1 i}\right)}{1-a_{1 i}-a_{2 i}+a_{1 i} b_{2 i}+a_{2 i} b_{1 i}}\right\rangle \mid i=1,2, \ldots, n\right\}
$$

Based on the conversion relationship between evidence theory and the intuitionistic fuzzy set in formulas (14)-(16), the combined result $m_{1} \oplus m_{2}$ of $m_{1}$ and $m_{2}$ is expressed as

$$
m_{1} \oplus m_{2}\left(\left\{\theta_{i}\right\}\right)=\left[\frac{a_{1 i} b_{2 i}+a_{2 i}\left(b_{1 i}-a_{1 i}\right)}{1-a_{1 i}-a_{2 i}+a_{1 i} b_{2 i}+a_{2 i} b_{1 i}}, 1-\frac{b_{1 i}\left(1-a_{2 i}\right)+\left(1-b_{2 i}\right)\left(b_{1 i}-a_{1 i}\right)}{1-a_{1 i}-a_{2 i}+a_{1 i} b_{2 i}+a_{2 i} b_{1 i}}\right], \quad(i=1,2, \ldots, n) .
$$

It is worth noting that when the combined result $m_{1} \oplus m_{2}$ is a nonnormalized interval BPA, it needs to be normalized according to formulas (4)-(7).

\section{A New Energy Vehicle Enterprise Investment Decision Model}

3.1. Construction of Decision-Making Index System. Since the actual conditions of companies in different industries or different life cycles are not the same, it is obviously not feasible to use a fixed index system to evaluate all enterprises' project investment decisions. Therefore, it is necessary to focus on the new energy vehicle enterprise investment projects studied in this article. Its characteristic is to establish an exclusive evaluation index system. A scientific and reasonable investment decision-making index system is the basis for solving research problems. The characteristics of investment projects of new energy automobile companies should be reflected as much as possible, such as a significant gap in key technology maturity, an uncertain market demand scale, the overreliance on government policy support, and the incomplete construction of related supporting facilities [30-32].

3.2. Acquisition of Decision Index Measurement. In actual investment decision-making problems, because the decision-making object is characterized by information uncertainty and ambiguity, the construction of a decision-making index system usually involves the design of qualitative indexes. It is difficult to collect information on qualitative indicators and accurately measure them with specific data. In most cases, project decision-making evaluators can only give a comprehensive fuzzy evaluation based on a comprehensive understanding of the investment status of the industry, combining the actual situation of the investment project and their own experience, knowledge, and preferences. This paper uses a questionnaire survey to provide the 
attribute information of each decision indicator to 500 employees in various departments of the enterprise. The employees choose one of the two evaluation options (such as "high" and "low," "strong" and "weak," and "big" and "small") that are set for each decision indicator in advance. By setting confirmatory questions for each evaluation option, the uncertainty of the evaluator's judgment is reduced. The feedback received from various evaluators is collected and organized. Ten authoritative experts in the new energy vehicle industry commented on the statistical results of the indicator evaluation and finally obtained the evaluation data of each decision indicator. Taking the "resource richness" indicator as an example, the first evaluation results of the obtained indicators are summarized in Table 1.

Obviously, the above statistical results conform to the definition of interval intuitionistic fuzzy numbers defined by interval intuitionistic fuzzy set theory and comprehensively consider the ambiguity of decision objects and the limitations of human cognition based on the degree of membership, nonmembership, and hesitation. Therefore, it is feasible to describe statistical results in the form of interval intuitionistic fuzzy numbers. Taking the interval intuitionistic fuzzy number $\alpha=\langle[0.572,0.748],[0.180,0.198]\rangle$ of the above statistical results as an example, the statistical results are described as follows.

Interval $\alpha=\langle[0.572,0.748]\rangle$ is the membership degree interval, and the difference between the upper and lower limits of 0.176 represents the length of the interval. This means that $57.2 \%$ of the evaluators believe that the project's resource richness is high, and $17.6 \%$ of the evaluators believe that the project's resource richness is high but cannot be completely determined. That is, the project's survey result of the high degree of resource richness is between 0.572 and 0.748 . Interval $\alpha=\langle[0.180,0.198]\rangle$ is the nonsubordination interval, and the difference between the upper and lower limits of 0.018 represents the length of the interval. This means that $18.0 \%$ of the evaluators believe that the project's resource richness is low, and $1.8 \%$ of the evaluators believe that the project's resource richness is low but cannot be completely determined. That is, the project's survey result of the low degree of resource richness is between 0.180 and 0.198 . The sum of the upper limit of the membership degree interval and the nonmembership degree interval is 0.946 . This means that $5.4 \%$ of evaluators did not give evaluations because it was difficult to judge the resource richness of the project, or they automatically abstained because they did not participate in the evaluation of the indicators.

To make the statistical results more authentic and reliable, 10 authoritative experts in the new energy vehicle industry are invited to comment on the first evaluation results of the above-obtained indicators. First, the attribute evaluation terms of decision objects are divided into five levels: "very poor," "poor," "medium," "good," and "very good." Second, the corresponding hesitation interval $\tilde{\pi}_{A}(x)$ is calculated according to the membership degree interval $\tilde{\mu}_{A}(x)=\left[\mu_{A}^{L}(x), \mu_{A}^{R}(x)\right]$ and nonmembership interval $\tilde{v}_{A}(x)=\left[v_{A}^{L}(x), v_{A}^{R}(x)\right]$ corresponding to different semantic information and formula 16. Finally, the final evaluation result is determined according to the interval intuitionistic fuzzy number form corresponding to each index evaluation term, as shown in Table 2.

Take the interval intuitionistic fuzzy number $\alpha=$ $\langle[0.572,0.748],[0.180,0.198]\rangle$ of the index of "resource richness" as an example. Suppose that, after discussion by 10 experts, it is agreed that the evaluation term level of the index "resource richness" is "very good"; then, the final evaluation result of the intuitionistic fuzzy number of the index interval is $\alpha=\langle[0.523,0.525],[0.185,0.223]\rangle$.

\subsection{Determination of Decision-Making Index Weights.} Determining the weight of decision-making indicators is a core issue in the investment decision-making process of new energy automobile companies, and it reflects the importance of the decision-making indicators to the entire investment decision-making indicator system. The investment decisionmaking index system constructed in this paper has an obvious hierarchical structure, and the selected indexes are all qualitative indexes without precise data. Considering that the role and influence of each index in each level are not the same, the corresponding weight should be given gradually according to the importance of the indicators. In recent years, scholars have proposed methods for determining the weight of many indicators [33-36]. This paper focuses on the actual situation of new energy automobile companies, using the structural entropy method based on entropy theory that combines subjective and objective valuation methods. Through the Delphi expert survey method and fuzzy analysis method to collect expert opinions, entropy calculation and "cognitive blindness" analysis were carried out on the index "typical ranking" formed by the experts' "ranking opinions" and the potential deviation data were processed. After normalizing the overall awareness, the relative importance ranking of the indicators at the same level can be obtained, and the relative importance ranking of each indicator, namely, the indicator weight, can be determined layer by layer [33]. The structural entropy method can effectively weaken the potential cognitive ambiguity of the subjective assignment method and reduce the uncertainty of the "typical ranking" structure formed by expert opinions, making the determination of the index weight more scientific and reliable.

3.3.1. Collect Expert Opinions and Form "Typical Ranking”. The Delphi method is used to collect opinions of several experts on the relative importance of different levels of indicators in the established investment decision-making indicator system. This paper assumes that $r$ experts participate in the survey and are included in the statistics of the relative importance of $m$ indicators at the same level. The feedback form of each expert corresponds to an indicator set $U=\left\{u_{1}, u_{2}, \ldots, u_{n}\right\}$, and each indicator set corresponds to a set of indicator ranking opinion data $\left\{x_{r 1}, x_{r 2}, \ldots, x_{r M}\right\}$. The index ranking opinion matrix formed by the feedback opinion form of $R$ experts on $M$ indicators is called the "typical ranking" matrix of experts, recorded as $X=\left(x_{r m}\right) R \times M(r=1,2, \ldots$, 
TABLE 1: Statistics of the results of the questionnaire survey on the evaluation of resource richness.

\begin{tabular}{|c|c|c|c|c|c|}
\hline Decision index & Evaluation options & Confirmatory question & Confirmatory options & Statistical results & Proportion \\
\hline \multirow{6}{*}{ Resource richness } & \multirow{2}{*}{ High } & $\begin{array}{l}\text { Please select "sure" if you } \\
\text { are absolutely sure }\end{array}$ & Sure & 286 & 0.572 \\
\hline & & $\begin{array}{l}\text { Please select "hesitate" if } \\
\text { you are not completely sure }\end{array}$ & Hesitate & 88 & 0.176 \\
\hline & \multirow{4}{*}{ Low } & $\begin{array}{l}\text { Please select "sure" if you } \\
\text { are absolutely sure }\end{array}$ & Sure & 90 & 0.180 \\
\hline & & $\begin{array}{l}\text { Please select "hesitate" if } \\
\text { you are not completely sure }\end{array}$ & Hesitate & 9 & 0.018 \\
\hline & & Not evaluated & & 27 & 0.054 \\
\hline & & Total & & 500 & 1.00 \\
\hline
\end{tabular}

TABLE 2: Index evaluation terms and their corresponding interval intuitionistic fuzzy number table.

\begin{tabular}{lrr}
\hline Semantic information & Interval intuitionistic fuzzy number & Values of $\alpha$ and $\beta$ \\
\hline Very poor (VP) & $\left\langle\widetilde{\mu}_{A}(x)-\alpha \widetilde{\pi}_{A}(x), \widetilde{v}_{A}(x)+\beta \widetilde{\pi}_{A}(x)\right\rangle$ & $\alpha=0.10, \beta=0.90$ \\
Poor (P) & $\left\langle\widetilde{\mu}_{A}(x)-\alpha \widetilde{\pi}_{A}(x), \widetilde{v}_{A}(x)+\beta \widetilde{\pi}_{A}(x)\right\rangle$ & $\alpha=0.30, \beta=0.70$ \\
Medium (M) & $\left\langle\widetilde{\mu}_{A}(x)-\alpha \widetilde{\pi}_{A}(x), \widetilde{v}_{A}(x)+\beta \widetilde{\pi}_{A}(x)\right\rangle$ & $\alpha=\beta=0.50$ \\
Good (G) & $\left\langle\widetilde{\mu}_{A}(x)-\alpha \widetilde{\pi}_{A}(x), \widetilde{v}_{A}(x)+\beta \widetilde{\pi}_{A}(x)\right\rangle$ & $\alpha=0.70, \beta=0.30$ \\
Very good (VG) & $\left\langle\widetilde{\mu}_{A}(x)-\alpha \widetilde{\pi}_{A}(x), \widetilde{v}_{A}(x)+\beta \widetilde{\pi}_{A}(x)\right\rangle$ & $\alpha=0.90, \beta=0.10$ \\
\hline
\end{tabular}

$R, m=1,2, \ldots, M)$, where $x_{r m}$ represents the evaluation of the importance of the $r$ th expert on the $m$ th index; $x_{r m}$ takes any natural number in $\{1,2, \ldots, n\}$ and corresponds to " 1 st choice, 2nd choice..., nth choice." The smaller the value is, the higher the importance of the index.

3.3.2. Analyze "Typical Ranking" Cognitive Blindness. The "typical ranking" of experts is the index ranking opinions formed by experts based on their own knowledge and experience. The evaluation data obtained are essentially the subjective opinions of experts. The cognitive blindness analysis of "typical ranking" can reasonably eliminate the information uncertainty caused by the subjective cognitive bias of expert opinions.

(1) The qualitative ranking of "typical ranking" is quantified as a membership function to determine the average degree of awareness.

Define the qualitative and quantitative conversion membership function of "typical ranking":

$$
\delta(I)=\frac{\ln (y-I)}{\ln (y-1)}
$$

where $I$ represents the number of qualitative rankings of indicators in the "typical ranking" of experts and $\delta$ is a variable defined on $[0,1] . \delta(I)$ represents the membership function value corresponding to $I$. $I=1,2, \ldots, m$, where $m$ is the maximum sequence number of the index. The quantitative conversion value $z_{r m}=\delta\left(x_{r m}\right)$ obtained by substituting the ranking number $I=x_{r m}$ into formula (22) is called the membership function of the ordinal number $I$. Its membership matrix is expressed as $Z=\left(z_{r m}\right) R \times M(r=1,2, \ldots, R, m=1,2, \ldots, M)$.

The "unanimous view" of the $R$ experts on the $m$ th indicator is called the average degree of awareness $z_{m}:$

$$
z_{m}=\frac{\sum_{r=1}^{R} z_{r m}}{R}
$$

(2) The recognition blindness of the "typical matrix" is analyzed to determine the overall recognition.

The uncertainty caused by the $r$ th expert's cognition of the $m$ th index is called "cognitive blindness," recorded as $Q_{m}$ :

$$
Q_{m}=\left|\frac{\left\{\left[\max \left\{z_{1 m}, z_{2 m}, \ldots, z_{R m}\right\}-z_{m}\right]+\left[\min \left\{z_{1 m}, z_{2 m}, \ldots, z_{R m}\right\}-z_{m}\right]\right\}}{2}\right|
$$

The overall knowledge of $R$ experts on the $m$ th index is recorded as $x_{m}$ :

$$
x_{m}=z_{m}\left(1-Q_{m}\right)
$$

From this, the evaluation vector $X=\left\{x_{1}, x_{2}, \ldots\right.$, $\left.x_{M}\right\}$ of $R$ experts on $m$ indicators is obtained.
3.3.3. Determine the Index Weight. Normalize formula (25) to calculate the weight coefficient of the $m$ th index at the same level, recorded as $\omega_{m}$ :

$$
\omega_{m}=\frac{x_{m}}{\sum_{m=1}^{M} x_{m}}
$$


where $\omega_{m}$ represents the consistency judgment of $R$ experts' opinions on the importance of index set $U=\left\{u_{1}, u_{2}, \ldots, u_{n}\right\}$, which satisfies $\omega_{m}>0$ and $\sum_{m=1}^{M} \omega_{m}=1 . W=\left\{\omega_{1}, \omega_{2}, \ldots\right.$, $\left.\omega_{M}\right\}$ is the weight vector of index set $U=\left\{u_{1}, u_{2}, \ldots, u_{n}\right\}$.

\subsection{Comprehensive Evaluation of the Attributes of Decision-} Making Indexes. The interval intuitionistic fuzzy number weighted arithmetic average operator (also called the "IIFWA operator") based on the interval intuitionistic fuzzy number algorithm realizes the integration of interval intuitionistic fuzzy information. Comprehensive evaluation of upper-level decision-making indicators by the organic combination of decision-making indicator interval intuitionistic fuzzy number and weight coefficient can make expert opinions tend to be centralized, thereby improving the consistency of the decision-making results [37].

The weighted arithmetic average operator of interval intuitionistic fuzzy number $\alpha_{j}=\left(\left[a_{j}, b_{j}\right],\left[c_{j}, d_{j}\right]\right)$ satisfies condition $\operatorname{IIFWA}_{\omega}\left(\alpha_{1}, \alpha_{2}, \ldots, \alpha_{n}\right)=\sum_{j=1}^{n} \omega_{j} \alpha_{j} . \Omega$ is the set of interval intuitionistic fuzzy numbers, $\omega=\left(\omega_{1}, \omega_{2}, \ldots\right.$, $\left.\omega_{n}\right)^{\mathrm{T}}$ is the weight vector of $\alpha_{j}$, and $\sum_{j=1}^{n} \omega_{j}=1, \omega_{j} \in(0,1)$. The interval intuitionistic fuzzy set using IIFWA operator integration can be expressed as

$$
f_{\omega}\left(\alpha_{1}, \alpha_{2}, \ldots, \alpha_{n}\right)=\left(\left[1-\prod_{j=1}^{n}\left(1-a_{j}\right)^{\omega j}, 1-\prod_{j=1}^{n}\left(1-b_{j}\right)^{\omega j}\right],\left[\sum_{j=1}^{n} c_{j}^{\omega j}, \sum_{j=1}^{n} d_{j}^{\omega j}\right]\right) .
$$

Suppose that the set of decision-making units is $X=$ $\left\{X_{1}, X_{2}, \ldots, X_{m}\right\}, X_{i}(i=1,2, \ldots, m)$ represents the $i$ th decision-making unit of the decision matrix. The attribute set of each decision-making unit is $C=\left\{C_{1}, C_{2}, \ldots, C_{n}\right\}, C_{j}(j=$ $1,2, \ldots, n)$ represents the $j$ th attribute of the decision index, and its weight $\omega_{j}$ satisfies $\sum_{j=1}^{n} \omega_{j}=1\left(\omega_{j} \in(0,1)\right)$. The characteristic information of decision unit $Y_{i}$ based on attribute $C_{j}$ in the form of interval intuitionistic fuzzy numbers is recorded as $\alpha_{i j}=\left\langle\left[a_{i j}, b_{i j}\right],\left[c_{i j}, d_{i j}\right]\right\rangle$.

(1) Construct evaluation information.

Construct evaluation information $\alpha_{i j}$ of each decision index attribute $Y_{j}$ in each decision unit $X_{i}$.

$$
\begin{aligned}
\alpha_{i j} & =\left\langle\left[a_{i j}, b_{i j}\right],\left[c_{i j}, d_{i j}\right]\right\rangle, \\
(i & =1,2, \ldots, m, j=1,2, \ldots, n) .
\end{aligned}
$$

(2) Calculate the comprehensive interval intuitionistic fuzzy number.

The weighted arithmetic average operator IIFWA of the interval intuitionistic fuzzy number in formula (27) is used to calculate the attributes of each decision index $Y_{j}$ integrated comprehensive interval intuitionistic fuzzy number $\beta_{i j}$.

$$
\begin{aligned}
\beta_{i j} & =\left\langle\left[e_{i j}, f_{i j}\right],\left[g_{i j}, h_{i j}\right]\right\rangle, \\
(i & =1,2, \ldots, m, j=1,2, \ldots, n) .
\end{aligned}
$$

(3) Obtain the interval intuitionistic fuzzy number.

The above steps are repeated, summarizing the comprehensive evaluation results of each interval intuitionistic fuzzy number $\beta_{i j}(i=1,2, \ldots, m, j=$ $1,2, \ldots, n)$ into the interval intuitionistic fuzzy number evaluation table.

3.5. Fusion Decision Index Evaluation Results. In the evaluation stage of decision-making indicators, using interval numbers to express the value of decision-making indicators can more objectively reflect the ambiguity of decisionmaking information. However, in the final decision-making stage, the direct use of interval intuitionistic fuzzy numbers is usually not convenient for decision-making. Using the interval BPA to express the value of the decision index attribute is beneficial to comprehensively reflect the ambiguity of decision information and facilitate decision-making. Therefore, this paper expresses the interval intuitionistic fuzzy number of the first-level decision index of each scheme in the form of interval BPA. The orthogonal sum operation is performed on intuitionistic fuzzy sets converted from interval BPA, and the final interval evidence combination result is obtained based on the relationship between the interval BPA and the intuitionistic fuzzy set. Therefore, this determines the final investment decision scheme.

\section{Analysis of Example}

4.1. Construction of Decision-Making Index System. Multiple characteristic factors that affect the investment decisionmaking of a new energy vehicle enterprise project together constitute an investment decision-making index system. In recent years, many domestic and foreign scholars have made beneficial explorations on the investment decision-making index system of new energy enterprises [38-42]. On the basis of the existing index system research, this paper combines the characteristics of new energy vehicle enterprise investment projects. Starting from two aspects of investment conditions and investment benefits, the fuzzy analytic hierarchy process (AHP) is used to establish a new energy vehicle enterprise investment decision-making index system based on eight standards: resources, policies, technology, market, industry, economy, society, and environment. Among them, the investment conditions in the first-level indicator layer describe the conditions that the enterprises should have for the investment, and the investment benefits describe the observability of the expected benefits of the investment. The above two first-level indicators are 
subdivided into a number of second-level and third-level indicators, and the decision information is comprehensively and delicately described by selecting indicators with typical characteristic attributes in the decision-making indicator system layer by layer. This decision-making index system can comprehensively and objectively analyze the investment decision-making problems of new energy vehicle enterprises, as shown in Table 3.

4.2. Acquisition of Decision Index Measurement. According to the questionnaire survey method described in Section 3.2, 10 authoritative experts in the field of new energy vehicle industry planning were invited to conduct a second evaluation of the statistical results of the above questionnaire survey. The intuitionistic fuzzy numbers of the three-level indicator are obtained, including battery electric vehicle $(\mathrm{BEV})$ project $\mathrm{X}_{1}$, hybrid electric vehicle (HEV) project $\mathrm{X}_{2}$, fuel cell electric vehicle (FCEV) project $\mathrm{X}_{3}$, and hydrogen-powered vehicle (HPV) project $\mathrm{X}_{4}$. Taking battery electric vehicle $(\mathrm{BEV})$ project $\mathrm{X}_{1}$ as an example, the threelevel indicator evaluation results are shown in Table 4.

The intuitionistic fuzzy numbers of the three-level decision-making index interval for battery electric vehicle $(\mathrm{BEV})$ project $\mathrm{X}_{1}$, hybrid electric vehicle $(\mathrm{HEV})$ project $\mathrm{X}_{2}$, fuel cell electric vehicle (FCEV) project $\mathrm{X}_{3}$, and hydrogenpowered vehicle (HPV) project $\mathrm{X}_{4}$ are summarized in Table 5.

4.3. Determination of the Weights of Decision-Making Indicators. Based on the actual situation of new energy vehicle enterprises, 10 authoritative experts in the field of the new energy vehicle industry are invited to make a "typical ranking" of the second- and third-level evaluation indicators. Based on the opinions of experts, the weights of the second and third levels of the new energy vehicle enterprise investment decision-making index system are determined through the structural entropy weight method. The threelevel indicators "resource richness $\mathrm{C}_{11}$ " and "resource availability $\mathrm{C}_{12}$ " are taken as examples to determine the index weight coefficient.

\subsubsection{Collect Expert Opinions and Form "Typical Ranking"}

(1) Each expert independently ranks the importance of indicators at various levels based on their own knowledge and experience and ensures that the ratings of the indicators at the same level are different. The survey of indicator weights is shown in Table 6.

(2) The collected expert ranking opinions are converted into a "typical ranking" matrix.

$$
A 1=\left[\begin{array}{llllllllll}
1 & 1 & 1 & 1 & 1 & 2 & 1 & 1 & 1 & 2 \\
2 & 2 & 2 & 2 & 2 & 1 & 2 & 2 & 2 & 1
\end{array}\right] .
$$

\subsubsection{Analyze "Typical Ranking" Cognitive Blindness}

(1) The qualitative ranking of "typical ranking" is quantified as a membership function and the average degree of recognition is calculated.

The maximum index number in the "typical sorting" matrix is 2 ; then, $y=2+2=4$ :

$$
\begin{aligned}
& \text { when } x_{r m}=1, \delta x_{r m} \\
& \qquad \begin{aligned}
\ln y-x_{r m} \\
\text { when } x_{r m}
\end{aligned}=\frac{\ln 4-1}{\ln 4-1}=1, \\
& =2, \delta x_{r m}=\frac{\ln y-x_{r m}}{\ln y-1} \\
& =\frac{\ln 4-2}{\ln 4-1}=0.6309 .
\end{aligned}
$$

The membership matrix $Z_{1}$ of the "typical ranking" matrix $A_{1}$ is

$$
\begin{aligned}
& Z_{1}=z_{r m} R M \\
& \begin{aligned}
= & \left.\begin{array}{lllll}
1 & 1 & 1 & 1 & 1 \\
0.6309 & 0.6309 & 0.6309 & 0.6309 & 0.6309 \\
0.6309 & 1 & 1 & 1 & 0.6309 \\
1 & 0.6309 & 0.6309 & 0.6309 & 1
\end{array}\right] .
\end{aligned}
\end{aligned}
$$

The average degree $z_{m}$ of knowledge on $\mathrm{C}_{11}$ and $\mathrm{C}_{12}$ is

$$
\begin{aligned}
z_{1} & \\
= & z_{11}+z_{21}+\cdots+z_{R 1} / R \\
= & 1+1+1+1+1+0.6309 \\
& +1+1+1+0.6309 / 10 \\
= & 0.9262, \\
z_{2} \quad & \\
= & z_{12}+z_{22}+\cdots+z_{R 2} / R \\
= & 0.6309+0.6309+0.6309 \\
& +0.6309+0.6309+1+0.6309 \\
& +0.6309+10.6309+0.6309 / 10 \\
= & 0.7047 .
\end{aligned}
$$

(2) The cognitive blindness of the "typical matrix" is analyzed. 
TABLE 3: Investment decision index system of new energy vehicle enterprises.

\begin{tabular}{|c|c|c|c|}
\hline Purpose & First-level indicators & Second-level indicators & Third-level indicators \\
\hline \multirow{14}{*}{$\begin{array}{l}\text { Investment } \\
\text { decision } \\
\text { indicators } \\
\text { for } \\
\text { new } \\
\text { energy } \\
\text { vehicle } \\
\text { enterprises }\end{array}$} & \multirow{12}{*}{$\begin{array}{l}\text { Investment } \\
\text { conditions } \mathrm{A}_{1}\end{array}$} & & Resource richness $\mathrm{C}_{11}$ \\
\hline & & Natural resources $B_{1}$ & Resource availability $\mathrm{C}_{12}$ \\
\hline & & Financing channels $B_{2}$ & Government financial support $C_{21}$ \\
\hline & & Financing channels $B_{2}$ & Bank credit support $\mathrm{C}_{22}$ \\
\hline & & & Technology development level $\mathrm{C}_{31}$ \\
\hline & & lecnnical SKills $\mathrm{B}_{3}$ & Technology maturity $\mathrm{C}_{32}$ \\
\hline & & Market environment & Market demand scale $\mathrm{C}_{41}$ \\
\hline & & $\mathrm{B}_{4}$ & Market competition intensity $\mathrm{C}_{42}$ \\
\hline & & Industrial & Industrial subsidy policy support $C_{51}$ \\
\hline & & environment $\mathrm{B}_{5}$ & Completeness of supporting facilities $\mathrm{C}_{52}$ \\
\hline & & Economic benefits $B_{6}$ & Enterprise asset profitability $\mathrm{C}_{61}$ \\
\hline & & & Enterprise capital profitability $\mathrm{C}_{62}$ \\
\hline & \multirow[t]{2}{*}{$\begin{array}{l}\text { Investment benefits } \\
\qquad \mathrm{A}_{2}\end{array}$} & Social benefits $B_{7}$ & $\begin{array}{c}\text { Benefits of enterprises occupying social and economic resources } C_{71} \\
\text { Benefits of enterprises submitting state finances and supporting social } \\
\text { welfare undertakings } C_{72}\end{array}$ \\
\hline & & $\begin{array}{l}\text { Environmental } \\
\text { benefits } B_{8}\end{array}$ & $\begin{array}{l}\text { Contribution to environmental protection } \mathrm{C}_{81} \\
\text { Ecological environment improvement degree } \mathrm{C}_{82}\end{array}$ \\
\hline
\end{tabular}

TABLE 4: New energy vehicle enterprises $\mathrm{X}_{1}$ investment project third-level indicators interval intuitionistic fuzzy number survey table.

\begin{tabular}{|c|c|c|c|c|c|c|c|c|}
\hline \multirow[t]{2}{*}{$\mathrm{X}_{1}$} & \multicolumn{2}{|c|}{$\begin{array}{l}\text { High or } \\
\text { strong }\end{array}$} & \multicolumn{2}{|c|}{ Low or weak } & \multirow{2}{*}{$\begin{array}{c}\text { Not } \\
\text { evaluated }\end{array}$} & \multirow[t]{2}{*}{ Interval intuitionistic fuzzy number } & \multirow{2}{*}{$\begin{array}{l}\text { Semantics } \\
\text { information }\end{array}$} & \multirow[t]{2}{*}{ Interval intuitionistic fuzzy } \\
\hline & Sure & Hesitate & Sure & Hesitate & & & & \\
\hline $\mathrm{C}_{11}$ & 286 & 88 & 90 & 9 & 27 & $<[0.572,0.748],[0.180,0.198]>$ & VG & $<[0.523,0.525],[0.185,0.223]>$ \\
\hline $\mathrm{C}_{12}$ & 261 & 39 & 136 & 16 & 48 & $<[0.522,0.600],[0.272,0.304]>$ & G & $<[0.455,0.456],[0.301,0.366]>$ \\
\hline $\mathrm{C}_{21}$ & 203 & 30 & 191 & 28 & 48 & $<[0.406,0.466],[0.382,0.438]>$ & M & $<[0.358,0.360],[0.430,0.544]>$ \\
\hline $\mathrm{C}_{22}$ & 198 & 37 & 189 & 32 & 44 & $<[0.396,0.470],[0.378,0.442]>$ & M & $<[0.352,0.357],[0.422,0.555]>$ \\
\hline $\mathrm{C}_{31}$ & 277 & 30 & 134 & 11 & 48 & $<[0.554,0.614],[0.268,0.290]>$ & G & $<[0.487,0.489],[0.297,0.343]>$ \\
\hline $\mathrm{C}_{32}$ & 206 & 44 & 180 & 41 & 29 & $<[0.412,0.500],[0.360,0.442]>$ & M & $<[0.383,0.386],[0.389,0.556]>$ \\
\hline $\mathrm{C}_{41}$ & 252 & 50 & 138 & 21 & 39 & $<[0.504,0.604],[0.276,0.318]>$ & G & $<[0.449,0.450],[0.299,0.384]>$ \\
\hline $\mathrm{C}_{42}$ & 259 & 46 & 124 & 14 & 57 & $<[0.518,0.610],[0.248,0.276]>$ & G & $<[0.438,0.446],[0.282,0.346]>$ \\
\hline $\mathrm{C}_{51}$ & 193 & 45 & 185 & 43 & 34 & $<[0.386,0.476],[0.370,0.456]>$ & M & $<[0.352,0.354],[0.404,0.578]>$ \\
\hline $\mathrm{C}_{52}$ & 132 & 20 & 269 & 46 & 33 & $<[0.264,0.304],[0.538,0.630]>$ & $\mathrm{P}$ & $<[0.244,0.245],[0.584,0.769]>$ \\
\hline $\mathrm{C}_{61}$ & 254 & 48 & 136 & 20 & 42 & $<[0.508,0.604],[0.272,0.312]>$ & G & $<[0.449,0.450],[0.297,0.378]>$ \\
\hline $\mathrm{C}_{62}$ & 185 & 40 & 188 & 38 & 49 & $<[0.370,0.450],[0.376,0.452]>$ & M & $<[0.321,0.323],[0.425,0.579]>$ \\
\hline $\mathrm{C}_{71}$ & 191 & 36 & 193 & 35 & 45 & $<[0.382,0.454],[0.386,0.456]>$ & M & $<[0.337,0.338],[0.431,0.572]>$ \\
\hline $\mathrm{C}_{72}$ & 255 & 39 & 140 & 14 & 52 & $<[0.510,0.588],[0.280,0.308]>$ & G & $<[0.437,0.441],[0.311,0.371]>$ \\
\hline $\mathrm{C}_{81}$ & 182 & 37 & 199 & 35 & 47 & $<[0.364,0.438],[0.398,0.468]>$ & M & $<[0.317,0.319],[0.445,0.587]>$ \\
\hline $\mathrm{C}_{82}$ & 193 & 38 & 195 & 36 & 38 & $<[0.386,0.462],[0.390,0.462]>$ & M & $<[0.348,0.350],[0.428,0.574]>$ \\
\hline
\end{tabular}

The cognitive blindness $Q_{m}$ of $C_{11}$ and $C_{12}$ is

$$
\begin{aligned}
Q_{1}= & \mid\{[\max \{1,1, \ldots, 0.6309\}-0.9262] \\
& +[\min \{1,1, \ldots, 0.6309\}-0.9262] / 2\} \mid \\
= & \left|\left\{\frac{[1-0.9262]+[0.6309-0.9262]}{2}\right\}\right| \\
= & 0.1108, \\
Q_{2}= & \mid\{[\max \{0.6309,0.6309, \ldots, 1\}-0.7047] \\
& +[\min \{0.6309,0.6309, \ldots, 1\}-0.7047] / 2\} \mid \\
= & \left|\left\{\frac{[1-0.7047]+[0.6309-0.7047]}{2}\right\}\right| \\
= & 0.1108 .
\end{aligned}
$$

The overall awareness $x_{m}$ of $\mathrm{C}_{11}$ and $\mathrm{C}_{12}$ is

$$
\begin{aligned}
x_{1}= & z_{1} 1-Q_{1}=0.9262 \\
& \times 1-0.1108=0.8236, \\
x_{2}= & z_{2} 1-Q_{2}=0.7047 \\
& \times 1-0.1108=0.6266 .
\end{aligned}
$$

4.3.3. Determine the Index Weight Indicators. The weight coefficient $\omega_{m}$ of the two third-level indicators $\mathrm{C}_{11}$ and $\mathrm{C}_{12}$ under the second-level indicator $\mathrm{B}_{1}$ is

$$
\begin{aligned}
& \omega_{1}=\frac{x_{1}}{\sum_{m=1}^{2} x_{m}}=\frac{0.8236}{(0.8236+0.6266)}=0.5679, \\
& \omega_{2}=\frac{x_{2}}{\sum_{m=1}^{2} x_{m}}=\frac{0.6266}{(0.8236+0.6266)}=0.4321 .
\end{aligned}
$$




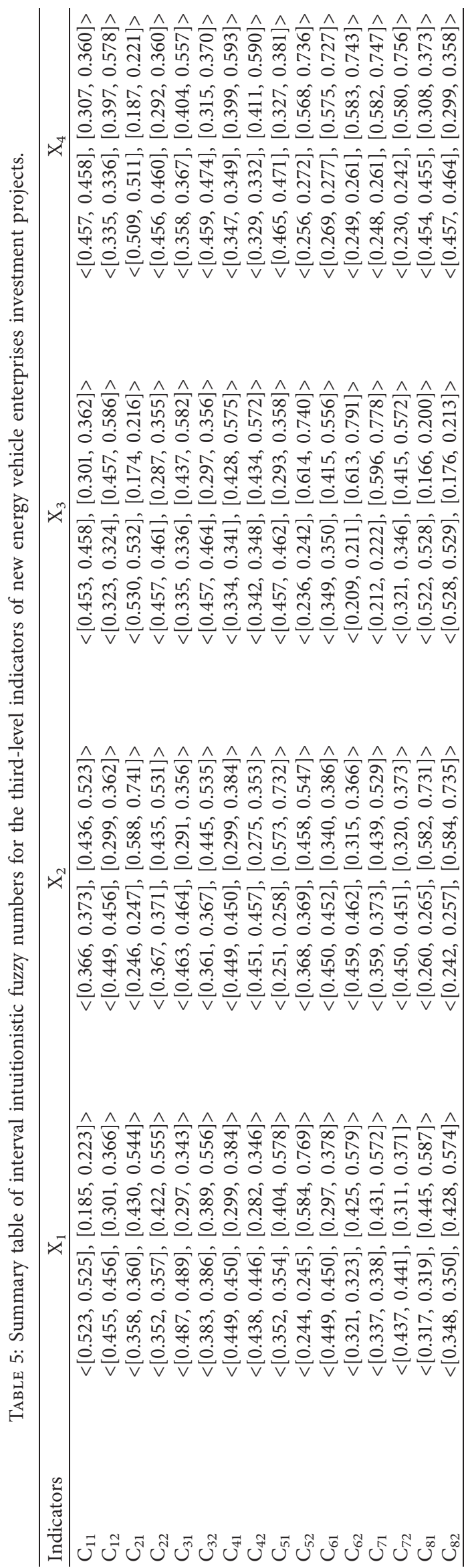


TABLE 6: Survey of the weights of investment decision-making indicators for new energy vehicle enterprises.

\begin{tabular}{|c|c|c|c|c|c|c|c|c|c|c|}
\hline \multirow{2}{*}{ Indicators } & \multicolumn{10}{|c|}{ Expert } \\
\hline & A & B & $\mathrm{C}$ & $\mathrm{D}$ & $\mathrm{E}$ & $\mathrm{F}$ & G & $\mathrm{H}$ & I & $\mathrm{J}$ \\
\hline $\mathrm{C}_{11}$ & 1 & 1 & 1 & 1 & 1 & 2 & 1 & 1 & 1 & 2 \\
\hline $\mathrm{C}_{12}$ & 2 & 2 & 2 & 2 & 2 & 1 & 2 & 2 & 2 & 1 \\
\hline
\end{tabular}

According to the above method, the weight coefficients of the second and third levels of the new energy vehicle enterprise investment decision index system are determined in sequence. The index weight evaluation results are shown in Table 7.

4.4. Comprehensive Evaluation of Decision Index Attributes. The method of combining the IIFWA operator and structural entropy weight method is used to integrate interval intuitionistic fuzzy information. The three-level indicators "resource richness $\mathrm{C}_{11}$ " and "resource availability $\mathrm{C}_{12}$ " are taken as examples to comprehensively evaluate the upperlevel two indicators "natural resources $\mathrm{B}_{1}$."

(1) Construct evaluation information.

The interval intuitionistic fuzzy number evaluation information $\alpha_{i j}(i=1, j=1,2)$ of the third-level indicators $\mathrm{C}_{11}$ and $\mathrm{C}_{12}$ is constructed.

$$
\begin{aligned}
& \alpha_{11}=\left\{\begin{array}{c}
\langle[0.523,0.525],[0.185,0.223]\rangle,\langle[0.366,0.373],[0.436,0.523]\rangle, \\
\langle[0.453,0.458],[0.301,0.362]\rangle,\langle[0.457,0.458],[0.307,0.360]\rangle
\end{array}\right\}, \\
& \alpha_{12}=\left\{\begin{array}{c}
\langle[0.455,0.456],[0.301,0.366]\rangle,\langle[0.449,0.456],[0.299,0.362]\rangle, \\
\langle[0.323,0.324],[0.457,0.586]\rangle,\langle[0.335,0.336],[0.397,0.578]\rangle
\end{array}\right\} .
\end{aligned}
$$

(2) Calculate the comprehensive interval intuitionistic fuzzy number.

Calculate the integrated interval intuitionistic fuzzy number $\beta_{i j}(i=1, j=1,2,3,4)$ of the second-level indicators $\mathrm{B}_{1}$.

$$
\begin{aligned}
& \beta_{11}=\left\langle\begin{array}{c}
{\left[1-(1-0.523)^{0.5679}(1-0.455)^{0.4321}, 1-(1-0.525)^{0.5679}(1-0.456)^{0.4321}\right],} \\
{\left[0.185^{0.5679} \times 0.301^{0.4321}, 0.223^{0.5679} \times 0.366^{0.4321}\right]}
\end{array}\right\rangle=\langle[0.495,0.496],[0.229,0.276]\rangle \text {, } \\
& \beta_{12}=\left\langle\begin{array}{c}
{\left[1-(1-0.366)^{0.5679}(1-0.449)^{0.4321}, 1-(1-0.373)^{0.5679}(1-0.456)^{0.4321}\right],} \\
{\left[0.436^{0.5679} \times 0.299^{0.4321}, 0.523^{0.5679} \times 0.362^{0.4321}\right]}
\end{array}\right\rangle=\langle[0.403,0.410],[0.371,0.446]\rangle \text {, } \\
& \beta_{13}=\left\langle\begin{array}{c}
{\left[1-(1-0.453)^{0.5679}(1-0.323)^{0.4321}, 1-(1-0.458)^{0.5679}(1-0.324)^{0.4321}\right],} \\
{\left[0.301^{0.5679} \times 0.457^{0.4321}, 0.362^{0.5679} \times 0.586^{0.4321}\right]}
\end{array}\right\rangle=\langle[0.400,0.404],[0.360,0.446]\rangle \text {, } \\
& \beta_{14}=\left\langle\begin{array}{c}
{\left[1-(1-0.4570)^{0.5679}(1-0.335)^{0.4321}, 1-(1-0.458)^{0.5679}(1-0.336)^{0.4321}\right],} \\
{\left[0.307^{0.5679} \times 0.397^{0.4321}, 0.360^{0.5679} \times 0.578^{0.4321}\right]}
\end{array}\right\rangle=\langle[0.407,0.408],[0.343,0.442]\rangle \text {. }
\end{aligned}
$$

(3) Obtain the intuitionistic fuzzy number of the second-level indicators.

The integrated interval intuitionistic fuzzy number $\beta_{i j}(i=1,2, \ldots, m, j=1,2, \ldots, n)$ of each secondlevel indicator is calculated in turn. The evaluation results are summarized in Table 8 .
(4) Obtain the intuitionistic fuzzy number of the first -level indicators.

Based on the above evaluation information, calculate the comprehensive interval intuitionistic fuzzy number of each first-level indicator after integration. The evaluation results are summarized in Table 9. 
TABLE 7: Summary table of index weights evaluation for investment decisions of new energy vehicle enterprises.

\begin{tabular}{|c|c|c|c|c|c|}
\hline Purpose & First-level indicators & Second-level indicators & Weights & Third-level indicators & Weights \\
\hline \multirow{15}{*}{$\begin{array}{l}\text { Investment } \\
\text { decision indicators } \\
\text { for } \\
\text { new } \\
\text { energy } \\
\text { vehicle } \\
\text { enterprises }\end{array}$} & \multirow{9}{*}{$\mathrm{A}_{1}$} & \multirow[t]{2}{*}{$\mathrm{B}_{1}$} & \multirow[t]{2}{*}{0.2309} & $\mathrm{C}_{11}$ & $\begin{array}{l}0.5679 \\
0.4321\end{array}$ \\
\hline & & & & $\begin{array}{l}\mathrm{C}_{12} \\
\mathrm{C}_{21}\end{array}$ & $\begin{array}{l}0.4321 \\
0.5453\end{array}$ \\
\hline & & $\mathrm{B}_{2}$ & 0.2341 & $\mathrm{C}_{22}$ & 0.4547 \\
\hline & & \multirow{2}{*}{$\mathrm{B}_{3}$} & \multirow{2}{*}{0.1640} & $\mathrm{C}_{31}$ & 0.4774 \\
\hline & & & & $\mathrm{C}_{32}$ & 0.5226 \\
\hline & & \multirow{2}{*}{$\mathrm{B}_{4}$} & \multirow{2}{*}{0.1362} & $\mathrm{C}_{41}$ & 0.5226 \\
\hline & & & & $\mathrm{C}_{42}$ & 0.4774 \\
\hline & & \multirow{2}{*}{$\mathrm{B}_{5}$} & \multirow{2}{*}{0.2348} & $\mathrm{C}_{51}$ & 0.5226 \\
\hline & & & & $\mathrm{C}_{52}$ & 0.4774 \\
\hline & \multirow{6}{*}{$\mathrm{A}_{2}$} & \multirow{2}{*}{$\mathrm{B}_{6}$} & \multirow{2}{*}{0.3564} & $\mathrm{C}_{61}$ & 0.4321 \\
\hline & & & & $\mathrm{C}_{62}$ & 0.5679 \\
\hline & & \multirow{2}{*}{$\mathrm{B}_{7}$} & \multirow{2}{*}{0.2939} & $\mathrm{C}_{71}$ & 0.4774 \\
\hline & & & & $\mathrm{C}_{72}$ & 0.5226 \\
\hline & & \multirow{2}{*}{$\mathrm{B}_{8}$} & \multirow{2}{*}{0.3498} & $\mathrm{C}_{81}$ & 0.5453 \\
\hline & & & & $\mathrm{C}_{82}$ & 0.4547 \\
\hline
\end{tabular}

4.5. Fusion of Decision Index Evaluation Results. On the premise of obtaining reasonable fusion results, to describe the fuzziness of decision information more delicately and improve decision efficiency, this paper introduces the interval evidence combination method based on intuitionistic fuzzy sets to fuse the interval intuitionistic fuzzy numbers of the first-level indicators. The fusion result was compared to clarify the order of the decision scheme and determine the final decision scheme.

(1) The uncertain interval intuitionistic fuzzy number in Table 9 is converted into certain interval BPA.

$$
\begin{aligned}
& m_{1}\left(\left\{\theta_{1}\right\}\right)=\left[a_{11}, b_{11}\right]=\left[\frac{0.405+0.407}{2}, 1-\frac{0.348+0.447}{2}\right]=[0.406,0.603], \\
& m_{1}\left(\left\{\theta_{2}\right\}\right)=\left[a_{12}, b_{12}\right]=\left[\frac{0.368+0.372}{2}, 1-\frac{0.416+0.513}{2}\right]=[0.370,0.536], \\
& m_{1}\left(\left\{\theta_{3}\right\}\right)=\left[a_{13}, b_{13}\right]=\left[\frac{0.408+0.413}{2}, 1-\frac{0.340+0.424}{2}\right]=[0.411,0.618], \\
& m_{1}\left(\left\{\theta_{4}\right\}\right)=\left[a_{14}, b_{14}\right]=\left[\frac{0.411+0.417}{2}, 1-\frac{0.338+0.429}{2}\right]=[0.414,0.616], \\
& m_{2}\left(\left\{\theta_{1}\right\}\right)=\left[a_{21}, b_{21}\right]=\left[\frac{0.367+0.369}{2}, 1-\frac{0.388+0.506}{2}\right]=[0.368,0.553], \\
& m_{2}\left(\left\{\theta_{2}\right\}\right)=\left[a_{22}, b_{22}\right]=\left[\frac{0.376+0.382}{2}, 1-\frac{0.415+0.497}{2}\right]=[0.379,0.544], \\
& m_{2}\left(\left\{\theta_{3}\right\}\right)=\left[a_{23}, b_{23}\right]=\left[\frac{0.265+0.380}{2}, 1-\frac{0.346+0.444}{2}\right]=[0.323,0.605], \\
& m_{2}\left(\left\{\theta_{4}\right\}\right)=\left[a_{24}, b_{24}\right]=\left[\frac{0.329+0.337}{2}, 1-\frac{0.463+0.580}{2}\right]=[0.333,0.479]
\end{aligned}
$$

Obviously, $m_{1}$ and $m_{2}$ are in accord with the concept of the first type of nonnormalized interval Bayesian BPA. It can be normalized as follows: 


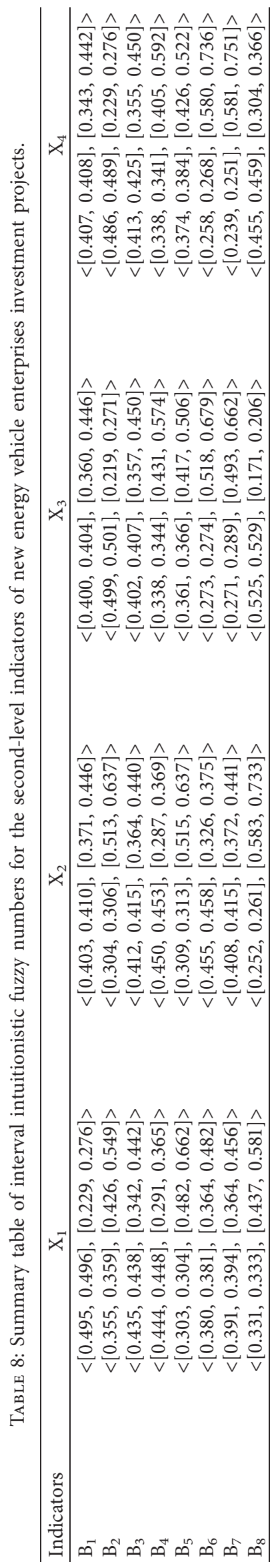


TABLE 9: Summary table of interval intuitionistic fuzzy numbers for the first-level indicators of new energy vehicle enterprises investment projects.

\begin{tabular}{lcccc}
\hline Indicators & \multicolumn{1}{c}{$\mathrm{X}_{1}$} & $\mathrm{X}_{2}$ & $\mathrm{X}_{3}$ & $\mathrm{X}_{4}$ \\
\hline \multirow{2}{*}{$\mathrm{A}_{1}$} & $<[0.405,0.407]$, & $<[0.368,0.372]$, & $<[0.408,0.413]$, & $<[0.411,0.417]$, \\
& {$[0.348,0.447]>$} & {$[0.416,0.513]>$} & {$[0.340,0.424]>$} & {$[0.338,0.429]>$} \\
$\mathrm{A}_{2}$ & $<[0.367,0.369]$, & $<[0.376,0.382]$, & $<[0.265,0.380]$, & $<[0.329,0.337]$, \\
& {$[0.388,0.506]>$} & {$[0.415,0.497]>$} & {$[0.346,0.444]>$} & {$[0.463,0.580]>$} \\
\hline
\end{tabular}

$$
\begin{aligned}
& \operatorname{Bet} P_{m 1}^{*}\left(\left\{\theta_{1}\right\}\right)=\left[a_{11}^{*}, b_{11}^{*}\right]=\left[\frac{a_{11}}{a_{11}+\sum_{j=1, j \neq 1}^{4} b_{1 j}}, \frac{b_{11}}{b_{11}+\sum_{j=1, j \neq 1}^{4} a_{1 j}}\right] \\
& =\left[\frac{0.406}{0.406+(0.536+0.618+0.616)}, \frac{0.603}{0.603+(0.370+0.411+0.414)}\right]=[0.186,0.335] \text {, } \\
& \operatorname{Bet} P_{m 1}^{*}\left(\left\{\theta_{2}\right\}\right)=\left[a_{12}^{*}, b_{12}^{*}\right]=\left[\frac{a_{12}}{a_{12}+\sum_{j=1, j \neq 2}^{4} b_{1 j}}, \frac{b_{12}}{b_{12}+\sum_{j=1, j \neq 2}^{4} a_{1 j}}\right] \\
& =\left[\frac{0.370}{0.370+(0.603+0.618+0.616)}, \frac{0.536}{0.536+(0.406+0.411+0.414)}\right]=[0.168,0.303] \text {, } \\
& \operatorname{Bet} P_{m 3}^{*}\left(\left\{\theta_{3}\right\}\right)=\left[a_{13}^{*}, b_{13}^{*}\right]=\left[\frac{a_{13}}{a_{13}+\sum_{j=1, j \neq 3}^{4} b_{1 j}}, \frac{b_{13}}{b_{13}+\sum_{j=1, j \neq 3}^{4} a_{1 j}}\right] \\
& =\left[\frac{0.411}{0.411+(0.603+0.536+0.616)}, \frac{0.618}{0.618+(0.406+0.370+0.414)}\right]=[0.190,0.342] \text {, }
\end{aligned}
$$$$
\operatorname{Bet} P_{m 1}^{*}\left(\left\{\theta_{4}\right\}\right)=\left[a_{14}^{*}, b_{14}^{*}\right]=\left[\frac{a_{14}}{a_{14}+\sum_{j=1, j \neq 4}^{4} b_{1 j}}, \frac{b_{14}}{b_{14}+\sum_{j=1, j \neq 4}^{4} a_{1 j}}\right]
$$$$
=\left[\frac{0.414}{0.414+(0.603+0.536+0.618)}, \frac{0.616}{0.616+(0.406+0.370+0.411)}\right]=[0.191,0.342] \text {, }
$$$$
\operatorname{Bet} P_{m 2}^{*}\left(\left\{\theta_{1}\right\}\right)=\left[a_{21}^{*}, b_{21}^{*}\right]=\left[\frac{a_{21}}{a_{21}+\sum_{j=1, j \neq 1}^{4} b_{2 j}}, \frac{b_{21}}{b_{21}+\sum_{j=1, j \neq 1}^{4} a_{2 j}}\right]
$$

$$
\begin{aligned}
& =\left[\frac{0.368}{0.368+(0.544+0.605+0.479)}, \frac{0.553}{0.553+(0.379+0.323+0.333)}\right]=[0.184,0.348] \text {, } \\
& \operatorname{Bet} P_{m 2}^{*}\left(\left\{\theta_{2}\right\}\right)=\left[a_{22}^{*}, b_{22}^{*}\right]=\left[\frac{a_{22}}{a_{22}+\sum_{j=1, j \neq 2}^{4} b_{2 j}}, \frac{b_{22}}{b_{22}+\sum_{j=1, j \neq 2}^{4} a_{2 j}}\right] \\
& =\left[\frac{0.379}{0.379+(0.553+0.605+0.479)}, \frac{0.544}{0.544+(0.368+0.323+0.333)}\right]=[0.188,0.347] \text {, } \\
& \operatorname{Bet} P_{m 2}^{*}\left(\left\{\theta_{3}\right\}\right)=\left[a_{23}^{*}, b_{23}^{*}\right]=\left[\frac{a_{23}}{a_{23}+\sum_{j=1, j \neq 3}^{4} b_{2 j}}, \frac{b_{23}}{b_{23}+\sum_{j=1, j \neq 3}^{4} a_{2 j}}\right] \\
& =\left[\frac{0.323}{0.323+(0.553+0.544+0.479)}, \frac{0.605}{0.605+(0.368+0.379+0.333)}\right]=[0.170,0.359] \text {, } \\
& \operatorname{Bet} P_{m 2}^{*}\left(\left\{\theta_{4}\right\}\right)=\left[a_{24}^{*}, b_{24}^{*}\right]=\left[\frac{a_{24}}{a_{24}+\sum_{j=1, j \neq 4}^{4} b_{2 j}}, \frac{b_{24}}{b_{24}+\sum_{j=1, j \neq 3}^{4} a_{2 j}}\right] \\
& =\left[\frac{0.333}{0.333+(0.553+0.544+0.605)}, \frac{0.479}{0.479+(0.368+0.379+0.323)}\right]=[0.164,0.309] \text {. }
\end{aligned}
$$


(2) Perform orthogonal sum operations on intuitionistic fuzzy sets.
The normalized interval Bayesian BPA is converted to the intuitionistic fuzzy set $M$ :

$$
\begin{aligned}
M_{1} & =\left\{\left\langle\theta_{i}, a_{1 i}^{*}, 1-b_{1 i}^{*}\right\rangle \mid i=1,2,3,4\right\} \\
& =\left\{\left\langle\theta_{1}, a_{11}^{*}, 1-b_{11}^{*}\right\rangle,\left\langle\theta_{2}, a_{12}^{*}, 1-b_{12}^{*}\right\rangle,\left\langle\theta_{3}, a_{13}^{*}, 1-b_{13}^{*}\right\rangle,\left\langle\theta_{4}, a_{14}^{*}, 1-b_{14}^{*}\right\rangle\right\} \\
& =\left\{\left\langle\theta_{1}, 0.186,1-0.335\right\rangle,\left\langle\theta_{2}, 0.168,1-0.303\right\rangle,\left\langle\theta_{3}, 0.190,1-0.342\right\rangle,\left\langle\theta_{4}, 0.191,1-0.342\right\rangle\right\} \\
& =\left\{\left\langle\theta_{1}, 0.186,0.665\right\rangle,\left\langle\theta_{2}, 0.168,0.697\right\rangle,\left\langle\theta_{3}, 0.190,0.658\right\rangle,\left\langle\theta_{4}, 0.191,0.658\right\rangle\right\} \\
M_{2} & =\left\{\left\langle\theta_{i}, a_{2 i}^{*}, 1-b_{2 i}^{*}\right\rangle \mid i=1,2,3,4\right\} \\
& =\left\{\left\langle\theta_{1}, a_{21}^{*}, 1-b_{21}^{*}\right\rangle,\left\langle\theta_{2}, a_{22}^{*}, 1-b_{22}^{*}\right\rangle,\left\langle\theta_{3}, a_{23}^{*}, 1-b_{23}^{*}\right\rangle,\left\langle\theta_{4}, a_{24}^{*}, 1-b_{24}^{*}\right\rangle\right\} \\
& =\left\{\left\langle\theta_{1}, 0.184,1-0.348\right\rangle,\left\langle\theta_{2}, 0.188,1-0.347\right\rangle,\left\langle\theta_{3}, 0.170,1-0.359\right\rangle,\left\langle\theta_{4}, 0.164,1-0.309\right\rangle\right\} \\
& =\left\{\left\langle\theta_{1}, 0.184,0.652\right\rangle,\left\langle\theta_{2}, 0.188,0.653\right\rangle,\left\langle\theta_{3}, 0.170,0.641\right\rangle,\left\langle\theta_{4}, 0.164,0.691\right\rangle\right\} .
\end{aligned}
$$

The orthogonal sum operation is performed on intuitionistic fuzzy sets $M 1$ and $M 2$ :

$$
\begin{aligned}
& M_{1} \oplus M_{2}=\left\{\left\langle\theta_{i}, \frac{a_{1 i}^{*} b_{2 i}^{*}+a_{2 i}^{*}\left(b_{1 i}^{*}-a_{1 i}^{*}\right)}{1-a_{1 i}^{*}-a_{2 i}^{*}+a_{1 i}^{*} b_{2 i}^{*}+a_{2 i}^{*} b_{1 i}^{*}}, \frac{b_{1 i}^{*}\left(1-a_{2 i}^{*}\right)+\left(1-b_{2 i}^{*}\right)\left(b_{1 i}^{*}-a_{1 i}^{*}\right)}{1-a_{1 i}^{*}-a_{2 i}^{*}+a_{1 i}^{*} b_{2 i}^{*}+a_{2 i}^{*} b_{1 i}^{*}}\right\rangle \mid i=1,2,3,4\right\} \\
& =\left\{\begin{array}{l}
\left\langle\theta_{1}, \frac{a_{11}^{*} b_{21}^{*}+a_{21}^{*}\left(b_{11}^{*}-a_{11}^{*}\right)}{1-a_{11}^{*}-a_{21}^{*}+a_{11}^{*} b_{21}^{*}+a_{21}^{*} b_{11}^{*}}, \frac{b_{11}^{*}\left(1-a_{21}^{*}\right)+\left(1-b_{21}^{*}\right)\left(b_{11}^{*}-a_{11}^{*}\right)}{1-a_{11}^{*}-a_{21}^{*}+a_{11}^{*} b_{21}^{*}+a_{21}^{*} b_{11}^{*}}\right\rangle, \\
\left\langle\theta_{2}, \frac{a_{12}^{*} b_{22}^{*}+a_{22}^{*}\left(b_{12}^{*}-a_{12}^{*}\right)}{1-a_{12}^{*}-a_{22}^{*}+a_{12}^{*} b_{22}^{*}+a_{22}^{*} b_{12}^{*}}, \frac{b_{12}^{*}\left(1-a_{22}^{*}\right)+\left(1-b_{22}^{*}\right)\left(b_{12}^{*}-a_{12}^{*}\right)}{1-a_{12}^{*}-a_{22}^{*}+a_{12}^{*} b_{22}^{*}+a_{22}^{*} b_{12}^{*}}\right\rangle, \\
\left\langle\theta_{3}, \frac{a_{13}^{*} b_{23}^{*}+a_{23}^{*}\left(b_{13}^{*}-a_{13}^{*}\right)}{1-a_{13}^{*}-a_{23}^{*}+a_{13}^{*} b_{23}^{*}+a_{23}^{*} b_{13}^{*}}, \frac{b_{13}^{*}\left(1-a_{23}^{*}\right)+\left(1-b_{23}^{*}\right)\left(b_{13}^{*}-a_{13}^{*}\right)}{1-a_{13}^{*}-a_{23}^{*}+a_{13}^{*} b_{23}^{*}+a_{23}^{*} b_{13}^{*}}\right\rangle, \\
\left\langle\theta_{4}, \frac{a_{14}^{*} b_{24}^{*}+a_{24}^{*}\left(b_{14}^{*}-a_{14}^{*}\right)}{1-a_{14}^{*}-a_{24}^{*}+a_{14}^{*} b_{24}^{*}+a_{24}^{*} b_{14}^{*}}, \frac{b_{14}^{*}\left(1-a_{24}^{*}\right)+\left(1-b_{14}^{*}\right)\left(b_{14}^{*}-a_{14}^{*}\right)}{1-a_{14}^{*}-a_{24}^{*}+a_{14}^{*} b_{24}^{*}+a_{24}^{*} b_{14}^{*}}\right\rangle
\end{array}\right\} \\
& =\left\{\begin{array}{l}
\left\langle\theta_{1}, \frac{0.186 * 0.348+0.184(0.335-0.186)}{1-0.186-0.184+0.186 * 0.348+0.184 * 0.335}, \frac{0.335(1-0.184)+(1-0.348)(0.335-0.186)}{1-0.186-0.184+0.186 * 0.348+0.184 * 0.335}\right\rangle, \\
\left\langle\theta_{2}, \frac{0.168 * 0.347+0.188(0.303-0.168)}{1-0.168-0.188+0.168 * 0.347+0.188 * 0.303}, \frac{0.303(1-0.188)+(1-0.347)(0.303-0.168)}{1-0.168-0.188+0.168 * 0.347+0.188 * 0.303}\right\rangle, \\
\left\langle\theta_{3}, \frac{0.190 * 0.359+0.170 *(0.342-0.190)}{1-0.190-0.170+0.190 * 0.359+0.170 * 0.342}, \frac{0.342(1-0.170)+(1-0.359)(0.342-0.190)}{1-0.190-0.170+0.190 * 0.359+0.170 * 0.342}\right\rangle \\
\left\langle\theta_{4}, \frac{0.191 * 0.309+0.164(0.342-0.191)}{1-0.191-0.164+0.191 * 0.309+0.164 * 0.342}, \frac{0.342(1-0.164)+(1-0.309)(0.342-0.191)}{1-0.191-0.164+0.191 * 0.309+0.164 * 0.342}\right\rangle
\end{array}\right\} \\
& =\left\{\left\langle\theta_{1}, 0.122,0.490\right\rangle,\left\langle\theta_{2}, 0.110,0.441\right\rangle,\left\langle\theta_{3}, 0.123,0.497\right\rangle,\left\langle\theta_{4}, 0.110,0.513\right\rangle\right\} \text {. }
\end{aligned}
$$

(3) Formation of interval evidence combination results. 
Based on the relationship between the interval BPA and the intuitionistic fuzzy set, the orthogonal sum operation result $M 1 \oplus M 2$ of the intuitionistic fuzzy set is replaced with the interval evidence combination result $m 1 \oplus m 2$.

$$
\begin{aligned}
& m_{1} \oplus m_{2}\left(\left\{\theta_{1}\right\}\right)=\left[\frac{a_{11}^{*} b_{21}^{*}+a_{21}^{*}\left(b_{11}^{*}-a_{11}^{*}\right)}{1-a_{11}^{*}-a_{21}^{*}+a_{11}^{*} b_{21}^{*}+a_{21}^{*} b_{11}^{*}}, 1-\frac{b_{11}^{*}\left(1-a_{21}^{*}\right)+\left(1-b_{21}^{*}\right)\left(b_{11}^{*}-a_{11}^{*}\right)}{1-a_{11}^{*}-a_{21}^{*}+a_{11}^{*} b_{21}^{*}+a_{21}^{*} b_{11}^{*}}\right] \\
& =[0.122,1-0.490]=[0.122,0.510], \\
& m_{1} \oplus m_{2}\left(\left\{\theta_{2}\right\}\right)=\left[\frac{a_{12}^{*} b_{22}^{*}+a_{22}^{*}\left(b_{12}^{*}-a_{12}^{*}\right)}{1-a_{12}^{*}-a_{22}^{*}+a_{12}^{*} b_{22}^{*}+a_{22}^{*} b_{12}^{*}}, 1-\frac{b_{12}^{*}\left(1-a_{22}^{*}\right)+\left(1-b_{22}^{*}\right)\left(b_{12}^{*}-a_{12}^{*}\right)}{1-a_{12}^{*}-a_{22}^{*}+a_{12}^{*} b_{22}^{*}+a_{22}^{*} b_{12}^{*}}\right] \\
& =[0.110,1-0.441]=[0.110,0.559] \text {, } \\
& m_{1} \oplus m_{2}\left(\left\{\theta_{3}\right\}\right)=\left[\frac{a_{13}^{*} b_{23}^{*}+a_{23}^{*}\left(b_{13}^{*}-a_{13}^{*}\right)}{1-a_{13}^{*}-a_{23}^{*}+a_{13}^{*} b_{23}^{*}+a_{23}^{*} b_{13}^{*}}, 1-\frac{b_{13}^{*}\left(1-a_{23}^{*}\right)+\left(1-b_{23}^{*}\right)\left(b_{13}^{*}-a_{13}^{*}\right)}{1-a_{13}^{*}-a_{23}^{*}+a_{13}^{*} b_{23}^{*}+a_{23}^{*} b_{13}^{*}}\right] \\
& =[0.123,1-0.497]=[0.123,0.503], \\
& m_{1} \oplus m_{2}\left(\left\{\theta_{4}\right\}\right)=\left[\frac{a_{14}^{*} b_{24}^{*}+a_{24}^{*}\left(b_{14}^{*}-a_{14}^{*}\right)}{1-a_{14}^{*}-a_{24}^{*}+a_{14}^{*} b_{24}^{*}+a_{24}^{*} b_{14}^{*}}, 1-\frac{b_{14}^{*}\left(1-a_{24}^{*}\right)+\left(1-b_{24}^{*}\right)\left(b_{14}^{*}-a_{14}^{*}\right)}{1-a_{14}^{*}-a_{24}^{*}+a_{14}^{*} b_{24}^{*}+a_{24}^{*} b_{14}^{*}}\right] \\
& =[0.110,1-0.513]=[0.110,0.487] \text {. }
\end{aligned}
$$

Obviously, the above interval evidence combination result $m_{1} \oplus m_{2}\left(\left\{\theta_{i}\right\}\right)(i=1,2,3,4)$ satisfies the normalization conditions.

(4) Comparison decision scheme.

The fused interval BPA is converted to classic BPA [24]:

$$
\begin{aligned}
& m_{12}\left(\left\{\theta_{1}\right\}\right)=\frac{(0.122+0.510)}{2}=0.316, \\
& m_{12}\left(\left\{\theta_{2}\right\}\right)=\frac{(0.110+0.559)}{2}=0.335, \\
& m_{12}\left(\left\{\theta_{3}\right\}\right)=\frac{(0.123+0.503)}{2}=0.313, \\
& m_{12}\left(\left\{\theta_{4}\right\}\right)=\frac{(0.110+0.487)}{2}=0.298 .
\end{aligned}
$$

The basic probability distribution function of battery electric vehicle (BEV) project $\mathrm{X}_{1}$ is 0.316 , the basic probability distribution function of hybrid electric vehicle (HEV) project $\mathrm{X}_{2}$ is 0.355 , the basic probability distribution function of fuel cell electric vehicle (FCEV) project $\mathrm{X}_{3}$ is 0.313 , and the basic probability distribution function of hydrogen-powered vehicle (HPV) project $\mathrm{X}_{4}$ is 0.298 . In summary, hybrid electric vehicle (HEV) project $\mathrm{X}_{2}$ is the optimal investment decision plan for new energy vehicle enterprises.

\section{Discussion}

To further reflect the rationality and superiority of the interval evidence combination method based on intuitionistic fuzzy sets, the following will compare the performance characteristics of this method with Lee and Zhu's method [21], Denoeux's method [22], Yager's method [23], Wang's method [24], and Sevastianov's method [25].

Lee and Zhu combined the interval BPA through generalized addition and generalized multiplication operations. This method needs to manually determine the parameters and is highly subjective. The choice of parameters will affect the final combination result. This method does not consider the normalization of interval BPA in the process of interval evidence combination. In addition, the combined results of the other five methods are all normalized interval BPAs. Denoeux constructs an optimization model to calculate the upper and lower bounds of the basic probability quality focusing on each focal element in the combined result. However, because this method does not satisfy the associative law, when fusing multiple interval BPAs, the fusion order determines the final combined result. Even if this problem is overcome to a certain extent through the normalization of the combined results, the interval span of each basic probability quality in the obtained results is large. It leads to a certain gap with the real result. Yager performs interval BPA combinations based on interval arithmetic operations. However, the combined result obtained by using this method may have the phenomenon that the upper 
bound is smaller than the lower bound, and the combined result cannot be normalized. Wang realizes the interval BPA combination by jointly optimizing the combination result of interval evidence and the normalization process. The fusion process of this method involves optimization models and multiple nonlinear programming models. Therefore, more realistic results can be obtained. However, its optimization algorithm is more complex, and there is still the problem of not satisfying the associative law. Sevastianov implemented a rule-based evidence reasoning framework and arithmetic operations of interval numbers, using the "extended zero interval" method to combine evidence from different intervals. The normalization of the combined result is realized by calculating the product of the interval probability and the normalization factor. The fusion process of this method only involves the arithmetic operation of interval numbers, so the algorithm is relatively simple. However, the interval probability of the normalized combination result may be greater than 1. Therefore, it cannot be used in multiple attribute decision-making. The interval evidence combination method based on intuitionistic fuzzy sets used in this paper is implemented on the basis of intuitionistic fuzzy calculations derived from evidence combination rules. This method satisfies commutative and associative laws. It meets the needs of time-domain evidence combination and can flexibly combine multiple interval evidence. Not only is the algorithm complexity low, but the fusion efficiency can be effectively improved under the premise of obtaining reasonable fusion results.

\section{Conclusions}

This paper regards the investment decision-making problem of new energy vehicle enterprises as a fuzzy evaluation problem of each investment project based on the enterprise investment decision-making index system. A new energy vehicle enterprise investment decision-making indicator system is built based on the exclusive characteristics of the enterprise investment project. The system comprehensively covers multiple characteristic factors that affect enterprises' project investment decisions. Due to the uncertainty of decision-making information, it is often difficult to obtain accurate data to provide accurate support for decisionmaking. The use of interval intuitionistic fuzzy numbers to represent the attributes of decision-making indicators can not only flexibly and delicately deal with the hesitation of decision-makers in the decision-making process but also intuitively and clearly reflect the degree of fuzzy decision information. Therefore, this paper takes the interval evidence combination method based on intuitionistic fuzzy sets as the research foundation and simulates the investment problem of new energy vehicle enterprises by comprehensively evaluating the index attributes of each decision plan. This verifies the rationality of the application of the interval intuitionistic fuzzy set investment decision-making model, solves the problem of information ambiguity and information loss in the decision-making process, and reduces the complexity of the fusion algorithm. It is convenient to extend it to application fields similar to multiattribute group decision-making and has important practical significance and application value for promoting enterprises to make investment decisions scientifically and rationally.

This paper on the research of interval basic probability assignment-based intuitionistic fuzzy set theory is still in the exploratory stage. Taking into account the complexity and diversity of the actual decision-making environment, future research will explore in depth the algorithm of interval intuitionistic fuzzy set theory and the improvement of the collective settlement and consider the construction of an investment decision-making index system that combines qualitative and quantitative indicators to further expand the application range of interval basic probability assignmentbased intuitionistic fuzzy set decision-making methods.

\section{Data Availability}

The data used to support the findings of this study are included within the article.

\section{Conflicts of Interest}

The authors declare that they have no competing financial interests.

\section{Acknowledgments}

This paper was supported by the National Social Science Fund of China (no. 17CGL007).

\section{References}

[1] C. W. Churchman, R. L. Ackoff, and E. L. Arnoff, Introduction to Operations Research, Wiley, New York, NY, USA, 1957.

[2] W. Liang, M. Goh, and Y. M. Wang, "Multi-attribute group decision making method based on prospect theory under hesitant probabilistic fuzzy environment," Computers \& Industrial Engineering, vol. 149, Article ID 106804, 2020.

[3] Z. Yang and H. Garg, "Interaction power partitioned maclaurin symmetric mean operators under q-rung orthopair uncertain linguistic information," International Journal of Fuzzy Systems, 2021.

[4] A. P. Petkova, A. Wadhwa, X. Yao, and S. Jain, "Reputation and decision making under ambiguity: a study of U.S. venture capital firms' investments in the emerging clean energy sector," Academy of Management Journal, vol. 57, no. 2, pp. 422-448, 2014.

[5] M. Montajabiha, "An extended PROMETHE II multi-criteria group decision making technique based on intuitionistic fuzzy logic for sustainable energy planning," Group Decision and Negotiation, vol. 25, no. 2, pp. 221-244, 2016.

[6] M. Alipour, S. Alighaleh, R. Hafezi, and M. Omranievardi, "A new hybrid decision framework for prioritizing funding allocation to Iran's energy sector," Energy, vol. 121, no. 15, pp. 388-402, 2017.

[7] L. A. Zadeh, "Fuzzy sets," Information and Control, vol. 8, no. 3, pp. 338-353, 1965.

[8] K. T. Atanassov, "Intuitionistic fuzzy sets," Fuzzy Sets and Systems, vol. 20, no. 1, pp. 87-96, 1986.

[9] M. Zhao, S. S. Qin, J. H. Xie et al., "Interval intuitionistic fuzzy multi-attribute group decision making method considering 
the risk preference of decision makers," Operations Research and Management Science, vol. 27, no. 1, pp. 7-16, 2018.

[10] Z. T. Kalender, H. Tozan, and O. Vayvay, "Prioritization of medical errors in patient safety management: framework using interval-valued intuitionistic fuzzy sets," Healthcare, vol. 8, no. 3, p. 265, 2020.

[11] S. Z. Zeng and D. D. Luo, "Research on interval intuitionistic fuzzy multiple attribute decision making method based on projection model," Operations Research and Management Science, vol. 29, no. 3, pp. 10-15, 2020.

[12] Y. Zheng, J. Xu, J. Xu, and H. Chen, "TOPSIS-based entropy measure for intuitionistic trapezoidal fuzzy sets and application to multi-attribute decision making," Mathematical Biosciences and Engineering, vol. 17, no. 5, pp. 5604-5617, 2020.

[13] Z. Yang and J. Chang, "A multi-attribute decision-makingbased site selection assessment algorithm for garbage disposal plant using interval q-rung orthopair fuzzy power Muirhead mean operator," Environmental Research, vol. 193, Article ID 110385, 2021.

[14] A. P. Dempster, "Upper and lower probabilities induced by a multivalued mapping," The Annals of Mathematical Statistics, vol. 38, no. 2, pp. 325-339, 1967.

[15] G. Shafer, A Mathematical Theory of Evidence, Princeton University Press, Princeton, NJ, USA, 1976.

[16] Y. Song, X. Wang, W. Quan, and W. Huang, "A new approach to construct similarity measure for intuitionistic fuzzy sets," Soft Computing, vol. 23, no. 6, pp. 1985-1998, 2019.

[17] Z. Yu, W. Chen, and C. Zhu, "Design of unmanned park vehicle decision-making system based on uncertainty information," IFAC-PapersOnLine, vol. 51, no. 31, pp. 924-929, 2018.

[18] W. Wang, Y. Yan, R. Zhang, Z. Wang, Y. Fan, and C. Yang, "Multi-attribute fusion algorithm based on improved evidence theory and clustering," Sensors, vol. 19, no. 19, p. 4146, 2019.

[19] Z. Yang, X. Li, and P. He, “A decision algorithm for selecting the design scheme for blockchain-based agricultural product traceability system in q-rung orthopair fuzzy environment," Journal of Cleaner Production, vol. 290, Article ID 125191, 2021.

[20] D. Wu and Y. Tang, "An improved failure mode and effects analysis method based on uncertainty measure in the evidence theory," Quality and Reliability Engineering International, vol. 36, no. 5, pp. 1786-1807, 2020.

[21] E. S. Lee and Q. Zhu, "An interval dempster-shafer approach," Computers \& Mathematics with Applications, vol. 24, no. 7, pp. 89-95, 1992.

[22] T. Denoeux, "Modeling vague beliefs using fuzzy-valued belief structures," Fuzzy Sets \& Systems, vol. 116, no. 2, pp. 167-199, 2000.

[23] R. R. Yager, "Dempster-Shafer belief structures with interval valued focal weights," International Journal of Intelligent Systems, vol. 16, no. 4, pp. 497-512, 2001.

[24] Y.-M. Wang and T. M. S. Elhag, "On the normalization of interval and fuzzy weights," Fuzzy Sets and Systems, vol. 157, no. 18, pp. 2456-2471, 2006.

[25] P. Sevastianov, L. Dymova, and P. Bartosiewicz, "A framework for rule-base evidential reasoning in the interval setting applied to diagnosing type 2 diabetes," Expert Systems with Applications, vol. 39, no. 4, pp. 4190-4200, 2012.

[26] X. N. Li, J. Liu, and Y. F. Song, "Research on the method of interval evidence combination in the framework of intuitionistic fuzzy," Systems Engineering-Theory \& Practice, vol. 39, no. 11, pp. 2906-2917, 2019.

[27] Y. Li, X. Y. Deng, and Y. Deng, "A new interval intuitionistic fuzzy set decision-making method: the perspective of interval evidence combination," Control and Decision, vol. 29, no. 06, pp. 1143-1147, 2014.

[28] K. Atanassov and G. Gargov, "Interval valued intuitionistic fuzzy sets," Fuzzy Sets and Systems, vol. 31, no. 3, pp. 343-349, 1989.

[29] S.-M. Chen, S.-H. Cheng, and C.-H. Chiou, "Fuzzy multiattribute group decision making based on intuitionistic fuzzy sets and evidential reasoning methodology," Information Fusion, vol. 27, pp. 215-227, 2016.

[30] S. J. Zhao, F. Q. Zhao, H. Hao et al., "China's new energy vehicle charging infrastructure development status and countermeasures," Forum on Science and Technology in China, vol. 10, pp. 97-104, 2017.

[31] X. Cao, Z. Y. Xing, and L. P. Zhang, "An evolutionary game analysis of the development of new energy vehicle industry under government regulation," Management Review, vol. 30, no. 9, pp. 82-96, 2018.

[32] Y. Q. Xiong and X. L. Li, "Differences in the role of new energy vehicle supply and demand policies in heterogeneous markets," Studies in Science of Science, vol. 37, no. 4, pp. 597-606, 2019.

[33] Q. Y. Cheng, "Structural entropy weight method for determining evaluation index weight," Systems Engineering-Theory \& Practice, vol. 30, no. 7, pp. 1225-1228, 2010.

[34] N. Zhang and G. Wei, "Extension of VIKOR method for decision making problem based on hesitant fuzzy set," Applied Mathematical Modelling, vol. 37, no. 7, pp. 4938-4947, 2013.

[35] S. C. Onar, B. Oztaysi, and C. Kahraman, "Strategic decision selection using hesitant fuzzy TOPSIS and interval type-2 fuzzy AHP: a case study," International Journal of Computational Intelligence System, vol. 7, no. 5, pp. 1002-1021, 2014.

[36] M. Kiliç and İ. Kaya, "The prioritisation of provinces for public grants allocation by a decision-making methodology based on type-2 fuzzy sets," Urban Studies, vol. 53, no. 4, pp. 755-774, 2016.

[37] Z. S. Xu, "Interval intuitionistic fuzzy information integration method and its application in decision-making," Control and Decision, vol. 2, pp. 215-219, 2007.

[38] Y. Çelikbilek and F. Tüysüz, “An integrated grey based multicriteria decision making approach for the evaluation of renewable energy sources," Energy, vol. 115, no. 1, pp. 1246-1258, 2016.

[39] A. Kumar, B. Sah, A. R. Singh et al., "A review of multi criteria decision making (MCDM) towards sustainable renewable energy development," Renewable and Sustainable Energy Reviews, vol. 69, pp. 596-609, 2017.

[40] G. Büyüközkan and Y. Karabulut, "Energy project performance evaluation with sustainability perspective," Energy, vol. 119, no. 15, pp. 549-560, 2017.

[41] M. Çolak and İ. Kaya, "Prioritization of renewable energy alternatives by using an integrated fuzzy MCDM model: a real case application for Turkey," Renewable and Sustainable Energy Reviews, vol. 80, pp. 840-853, 2017.

[42] H.-G. Peng, K.-W. Shen, S.-S. He, H.-Y. Zhang, and J.-Q. Wang, "Investment risk evaluation for new energy resources: an integrated decision support model based on regret theory and ELECTRE III," Energy Conversion and Management, vol. 183, pp. 332-348, 2019. 